\title{
əPolarimetric and Electrical Structure of the 19 May 2013 Edmond-Carney, Oklahoma, Tornadic Supercell
}

\author{
Milind Sharma, ${ }^{\mathrm{a}}$ Robin L. TAnamachi, ${ }^{\mathrm{a}}$ Eric C. Bruning, ${ }^{\mathrm{b}}$ And Kristin M. Calhoun ${ }^{\mathrm{c}}$ \\ ${ }^{a}$ Department of Earth, Atmospheric, and Planetary Sciences, Purdue University, West Lafayette, Indiana \\ ${ }^{\mathrm{b}}$ Department of Geosciences, Texas Tech University, Lubbock, Texas \\ ${ }^{\mathrm{c}}$ National Severe Storms Laboratory, Norman, Oklahoma
}

(Manuscript received 27 August 2020, in final form 5 April 2021)

\begin{abstract}
We demonstrate the utility of transient polarimetric signatures $\left(Z_{\mathrm{DR}}\right.$ and $K_{\mathrm{DP}}$ columns, a proxy for surges in a thunderstorm updraft) to explain variability in lightning flash rates in a tornadic supercell. Observational data from a WSR-88D and the Oklahoma lightning mapping array are used to map the temporal variance of polarimetric signatures and VHF sources from lightning channels. It is shown, via three-dimensional and cross-sectional analyses, that the storm was of inverted polarity resulting from anomalous electrification. Statistical analysis confirms that mean flash area in the $Z_{\mathrm{DR}}$ column region was 10 times smaller than elsewhere in the storm. On an average, 5 times more flash initiations occurred within $Z_{\mathrm{DR}}$ column regions, thereby supporting existing theory of an inverse relationship between flash initiation rates and lightning channel extent. Segmentation and object identification algorithms are applied to gridded radar data to calculate metrics such as height, width, and volume of $Z_{\mathrm{DR}}$ and $K_{\mathrm{DP}}$ columns. Variability in lightning flash rates is best explained by the fluctuations in $Z_{\mathrm{DR}}$ column volume with a Spearman's rank correlation coefficient value of 0.72 . The highest flash rates occur in conjunction with the deepest $Z_{\mathrm{DR}}$ columns (up to $5 \mathrm{~km}$ above environmental melting level) and largest volumes of $Z_{\mathrm{DR}}$ columns extending up to the $-20^{\circ} \mathrm{C}$ level ( $3 \mathrm{~km}$ above the melting level). Reduced flash rates toward the end of the analysis are indicative of weaker updrafts manifested as low $Z_{\mathrm{DR}}$ column volumes at and above the $-10^{\circ} \mathrm{C}$ level. These findings are consistent with recent studies linking lightning to the interplay between storm dynamics, kinematics, thermodynamics, and precipitation microphysics.
\end{abstract}

SIGNIFICANCE STATEMENT: Lightning is a manifestation of collisions between hydrometeor species, especially ice crystals and graupel. There still exist gaps in our understanding of the physical processes that link macroscopic properties of storms and their electrification characteristics. This study exploits dual-polarization radar signatures to characterize the temporal variability in the microphysical and electrical properties of a tornadic supercell. This particular storm maintained an inverted polarity charge structure throughout its mature phase. Pulses in the storm's updraft (inferred from behavior of differential reflectivity columns) were associated with jumps in lightning flash rates. Finally, we show that the time variations in lightning activity can be explained by changes in differential reflectivity column volume and height.

KEYWORDS: Lightning; Severe storms; Atmospheric electricity; Cloud microphysics; Data processing; Radars/Radar observations

\section{Introduction}

Exploitation of multisensor observational analyses of thunderstorms has established the use of lightning activity as an additional metric for predicting the onset of severe weather (Goodman et al. 1988; MacGorman et al. 1989; Williams et al. 1999; Schultz et al. 2009; Darden et al. 2010; Schultz et al. 2017; Tian et al. 2019; Rudlosky et al. 2019; Bruning et al. 2019). Lightning jumps (rapid increase in total lightning flash rates), in particular, have been observed to occur tens of minutes prior to reports of severe weather (Gatlin and Goodman 2010; Schultz et al. 2011; Metzger and Nuss 2013; Rudlosky and Fuelberg 2013; Chronis et al. 2015; Miller et al. 2015; Farnell

¿ Denotes content that is immediately available upon publication as open access.

Corresponding author: Milind Sharma, sharm261@purdue.edu et al. 2017). However, the above studies indicate that a major limitation of using lightning jumps in isolation as a prognostic indicator for nowcasting severe weather is the large variability in the probability of detection (POD) of severe weather events combined with relatively high false alarm ratio (FAR). For example, Miller et al. (2015) and Murphy (2017) reported a POD of $>0.85$ and 0.499 , respectively; however, FAR values were in the same range of $>0.85$ for both. Several reasons could explain this variability, namely, sample size of thunderstorms, geographic diversity of storms sampled, and disproportional representation of severe and nonsevere storms in the sample (Murphy 2017). Since lightning jumps are a manifestation of the mixed-phase updraft intensification, it is pertinent to focus on the evolution of storm kinematics and microphysics to understand the physical basis for typical lightning signatures of severe storms (Carey and Rutledge 2000; Lang and Rutledge 2002; Deierling et al. 2008; Deierling and Petersen 2008; Lund et al. 2009; Emersic et al. 2011; Calhoun et al. 2013; Schultz et al. 2015, 2017). Our motivation in this study is to analyze 
these storm-scale properties for the case of a cyclic supercell, and determine underlying physical linkages between evolution of storm updrafts and electrification characteristics, if any.

The intensity and strength of convective updrafts plays a crucial role in the noninductive charging (NIC) between icephase hydrometeors, mainly graupel and ice crystals (Latham and Dye 1989; Takahashi et al. 1999; Latham et al. 2007; Reinhart et al. 2014). Collisional charge transfer between these hydrometeors species is capable of producing observed electric fields in thunderstorms. The sign of charge polarity on rebounding ice particles is thought to be explained by the relative diffusional growth rate theory (RDGR): the hydrometeor experiencing a higher vapor diffusional growth rate is charged positively during such collisions (Baker et al. 1987; Dash et al. 2001). Two primary factors that govern the growth rate and subsequent charging of these hydrometeors are the ambient environmental temperature and supercooled liquid water concentration (SLWC) (Takahashi 1978; Berdeklis and List 2001; Saunders et al. 2006; Emersic and Saunders 2010). As per the NIC-RDGR mechanism, graupel gains positive charge polarity in warmer and wetter regions of the storm. The charge polarity reverses at colder temperatures and in drier regions, thereby promoting negative charging of graupel at higher altitudes and/or in regions with insufficient supercooled water for rapid diffusional growth of graupel.

The charge structure within updraft regions is explainable by invoking the NIC-RDGR mechanism. This is because the thermodynamical state of boundary layer governs vertical accelerations in updraft cores responsible for moisture flux transport to the mixed-phase region. Bruning et al. (2014) argued that thunderstorms experience a continuum of vertical charge profiles, which are largely influenced by factors such as environmental thermodynamics, updraft strength, and liquid depletion rates along updraft trajectories. They suggested that evolving nature of storm precipitation structure, dynamics, and kinematics can be responsible for transition from a normal tripole (midlevel negative charge between an upper and lower positive charge layer) to an inverted tripole. A number of studies have reported storms with "inverted" charge layer configurations (anomalous or reverse polarities from normal tripole), defined as the middle region (roughly between $-10^{\circ}$ and $-25^{\circ} \mathrm{C}$ ) being positively charged with an upper region dominated by negative charge (Marshall and Rust 1991; Rust and MacGorman 2002; Lang et al. 2004; Rust et al. 2005; MacGorman et al. 2005; Wiens et al. 2005; Weiss et al. 2008; Stough and Carey 2020).

A characteristic difference between normal- and invertedpolarity thunderstorms is the predominance of inverted-polarity intracloud (IC) lightning and a higher rate of positive cloud-toground $(+\mathrm{CG})$ flashes in the latter cases. Several theories have been proposed to explain this causality relationship; however, all invoke the role of riming rates of graupel in the mixed-phase region as a factor for inverted polarity structure (Knapp 1994; Carey et al. 2003; MacGorman et al. 2005; Williams et al. 2005; Carey and Buffalo 2007; MacGorman et al. 2008). To summarize the findings from these studies, multiple microphysical pathways can contribute to the variability in distribution of cloud liquid water content and graupel riming rates e.g., 1) shallower warm cloud depth (WCD) resulting in lower depletion rates due to collision-coalescence processes and more liquid water available for riming, 2) higher lifting condensation level correlated with strong updrafts (resulting in higher condensation rates increasing the likelihood of positive charging of graupel (Williams et al. 2005), 3) reduced recycling of cloud droplets in the main updraft (resulting in lower accretion of cloud water), or 4) reduced concentration of graupel (resulting in reduced competition for liquid water in the mixed-phase region). However, Chmielewski et al. (2018) showed that instability (i.e., CAPE as a bulk estimate of updraft strength) and WCD are not sufficient conditions to explain observed charged structures. Comparing 30 different ordinary and multicellular storms that occurred in a mesoscale environment with similar CAPE values, they found that storms with inverted polarity actually had larger values of WCD. They attributed this counterintuitive behavior to possible dry air entrainment in inverted polarity storms in or around the cloud base level. In other words, entrainment led to the formation of smaller drops, providing a higher amount of supercooled water for positive charging of graupel in the midlevels of such storms.

Spatiotemporal analysis of charge structure in supercell thunderstorms is challenging due to the inherent 3D airflow. Bruning et al. (2010) found multiple charge structures in adjacent regions of a supercell at the same time with regions of opposite polarity aligned horizontally adjacent to each other at the same altitude. This behavior was attributed to difference in graupel charge polarity under different NIC regimes and differential advection and sedimentation of hydrometeors upon charge separation. Schultz et al. (2017) argued that storm properties that are well correlated to total flash rate on longer time scales (e.g., maximum updraft speed) may not represent the same mechanisms which result in transient fluctuations in flash rates, such as lightning jumps. It may therefore be more meaningful to track time-dependent growth of storm features.

Observational analyses using dual-Doppler polarimetric radar and three-dimensional lightning mapping data for severe thunderstorms have successfully demonstrated the intimate correlation between evolution of flash rates and storm properties such as graupel mass or flux, graupel volume, maximum updraft velocity, and updraft volume (Carey and Rutledge 1996, 2000; Lang and Rutledge 2002; Deierling et al. 2008; Deierling and Petersen 2008; Payne et al. 2010; Calhoun et al. 2013; Schultz et al. 2015; Mecikalski et al. 2015; Carey et al. 2019). A major limitation of many such studies has been underrepresentation of geographically diverse storms, small sample size, and lack of a comprehensive dataset with representative sampling of storms spanning a wide spectrum of flash rates. Consequently, statistical relationships such as flash rate parameterization against radar derived kinematical or microphysical parameters (discussed above) are highly biased when applied to other datasets (Carey et al. 2019). Moreover, it is not often that multi-Doppler observations are available for retrieval of vertical velocity structure at high temporal resolution ( $<1 \mathrm{~min}$ ), hindering analysis of the interrelationships between kinematical, microphysical, and electrical evolution of severe storms.

Convective storm updrafts can easily loft small raindrops above the environmental $0^{\circ} \mathrm{Clevel}$, thereby adding liquid water to the mixed-phase region which plays an important role for 
charging of hydrometeors. Availability of ice nuclei and Hallett-Mossop (Hallett and Mossop 1974) splintering processes control the ice crystal number concentration in the mixed-phase region. Growth of ice crystals is conditioned by the availability of liquid water as water vapor diffuses from supercooled liquid water to ice crystals (i.e., the so-called Wegener-Bergeron-Findeisen mechanism; after Wegener 1911; Bergeron 1935; Findeisen 1938), and accretion of supercooled water on ice crystals leads to formation of graupel (Heymsfield 1978). Some of the supercooled drops may freeze and acquire a water-coat during collisions with other supercooled drops resulting in accelerated riming as small hail or graupel which further contributes to cloud electrification (Bringi et al. 1996). Therefore, understanding the freezing process of lofted liquid hydrometeors is crucial for inferring any role and contribution of microphysical processes in lightning activity (Jameson et al. 1996; Bringi et al. 1997; Carey and Rutledge 2000; Mecikalski et al. 2015, among others).

As small droplets get lofted in the updraft, they collect cloud water and start descending along the updraft periphery. Some of these raindrops recirculate in the updraft and partially freeze, resulting in hydrometeors with large liquid water fraction $(>60 \%)$. The process of lofting of liquid drops is often visible as a narrow columnar region in the differential reflectivity field from polarimetric radar data, commonly known as the $Z_{\mathrm{DR}}$ column (Hall et al. 1984; Illingworth et al. 1987; Caylor and Illingworth 1987; Tuttle et al. 1989; Herzegh and Jameson 1992; Brandes et al. 1995; Hubbert et al. 1998; Smith et al. 1999; Kumjian and Ryzhkov 2008; Kumjian et al. 2014). A number of other studies using weather radar and in situ measurements have confirmed that the extension of $Z_{\mathrm{DR}}$ columns above the environmental melting level are a manifestation of low concentrations of large (diameter $>4 \mathrm{~mm}$ ) supercooled raindrops mixed with ice crystals, graupel, and hail undergoing wet growth (e.g., Illingworth et al. 1987; Bringi et al. 1997; Loney et al. 2002; Kumjian et al. 2010, and references therein).

Specific differential phase $\left(K_{\mathrm{DP}}\right)$ columns have also been reported in supercells (Hubbert et al. 1998; Loney et al. 2002). Specific differential phase $K_{\mathrm{DP}}$ is directly proportional to liquid water content (Kumjian and Ryzhkov 2008; Ryzhkov and Zrnić 2019). Size sorting of drops by storm-relative winds results in a horizontal gradient in the drop size distribution, with lower concentration of big drops near the updraft relative to other parts of the storm, and higher concentration of smaller drops away from the updraft (Dawson et al. 2015). The eastern flank of supercellular updraft region with larger drops exhibits higher $Z_{\mathrm{DR}}$ values relative to other parts of the storm at the same altitude (Brandes et al. 1995; Bringi et al. 1997; Loney et al. 2002). Somewhat analogously, the western flank of updraft containing a relatively high concentration of small drops mixed with wet graupel or hail exhibits high $K_{\mathrm{DP}}$ values. To summarize, $Z_{\mathrm{DR}}$ and $K_{\mathrm{DP}}$ columns are a manifestation of deep convective updrafts. However, the two are often found to be spatially offset in supercells. While $Z_{\mathrm{DR}}$ columns are representative of large raindrops and ice particles undergoing wet growth, $K_{\mathrm{DP}}$ columns are more representative of drops $(>2 \mathrm{~mm})$ shed from wet-oriented particles (Loney et al. 2002; Kumjian and Ryzhkov 2008).
Both $Z_{\mathrm{DR}}$ and $K_{\mathrm{DP}}$ columns have been studied in some detail in the past, especially the utility of $Z_{\mathrm{DR}}$ column height trends for predicting the onset of severe weather including tornadogenesis (Picca et al. 2010, 2015; Snyder et al. 2015). Carey and Rutledge (2000) hypothesized that increased updraft strength enables greater condensate production in the mixed-phase zone, resulting in more ice mass aloft, thereby facilitating NIC mechanism and enhanced lightning activity. Deeper $Z_{\mathrm{DR}}$ columns in such cases would indicate increase in mixed-phase liquid water content promoting enhanced riming and positive charging of ice hydrometeors. Moreover, freezing of supercooled raindrops at the top of $Z_{\mathrm{DR}}$ columns can also provide a microphysical pathway for growth of millimeter size graupel and hail contributing to NIC and lightning production. Mecikalski et al. (2015) analyzed lightning flash rates in a multicellular storm and found contemporaneous surges in updraft intensity and $Z_{\mathrm{DR}}$ values extending higher in the mixed-phase regions. Additionally, Lier-Walqui et al. (2016), through their analysis of $K_{\mathrm{DP}}$ columns as a proxy for convective updrafts, found that the volume of $K_{\mathrm{DP}}$ columns correlated well with the updraft mass flux, which has been reported as a relevant kinematic variable to predict lightning flash rates (Wiens et al. 2005; Deierling and Petersen 2008).

The purpose of this paper is to quantify the utility and effectiveness of temporal variations in $Z_{\mathrm{DR}}$ and $K_{\mathrm{DP}}$ column volume for diagnosing the flash rate and size variability in a tornadic supercell. We hypothesize that since the height of $Z_{\mathrm{DR}}$ columns is directly related to updraft strength (Kumjian et al. 2014), it can be used to explain the variability in flash rates and spatial distribution of lightning activity more than $K_{\text {DP }}$ columns. To test this hypothesis, we develop a methodology for objectively identifying and tracking salient storm features, determining space-time distribution and properties of lightning inside and outside the updraft core (as inferred by $Z_{\mathrm{DR}}$ and $K_{\mathrm{DP}}$ columns). We demonstrate this methodology for the case of the Edmond-Carney, Oklahoma, tornadic supercell on 19 May 2013. Our eventual aim is to apply these methods to a larger sample of supercells spanning multiple years and climatic regimes.

\section{Synoptic setup and storm life cycle}

The environment on the morning of 19 May 2013 appeared conducive to a severe weather episode over Oklahoma. A synoptic-scale trough axis over the southern Rockies ejected a midlevel jet eastward over northwestern Texas and central Oklahoma early in the day (Fig. 1a). Strong flow at mid- and low levels provided deep layer $(0-6 \mathrm{~km})$ bulk shear in excess of $50 \mathrm{kt}\left(1 \mathrm{kt} \approx 0.51 \mathrm{~m} \mathrm{~s}^{-1}\right)$ over central Oklahoma (Fig. 1b). A low-level jet at $850 \mathrm{hPa}$ with winds greater than $30 \mathrm{kt}$ provided sufficient low-level moisture, shear (Fig. 1c), and 0$1-\mathrm{km} \mathrm{SRH}$ in excess of $100 \mathrm{~m}^{2} \mathrm{~s}^{-2}$ (Fig. 1d) to support supercells. Strong surface heating resulted in MUCAPE values in excess of $4000 \mathrm{~J} \mathrm{~kg}^{-1}$, strong enough for rapid intensification of convective updrafts (Fig. 1e). The 1200 UTC radiosounding from Norman (Fig. 1f) exhibited CIN values in excess of $-100 \mathrm{~J} \mathrm{~kg}^{-1}$ within a capping layer extending from 950 to $650 \mathrm{hPa}$. This capping inversion eroded significantly by 1800 UTC due to the boundary layer mixing as the day 


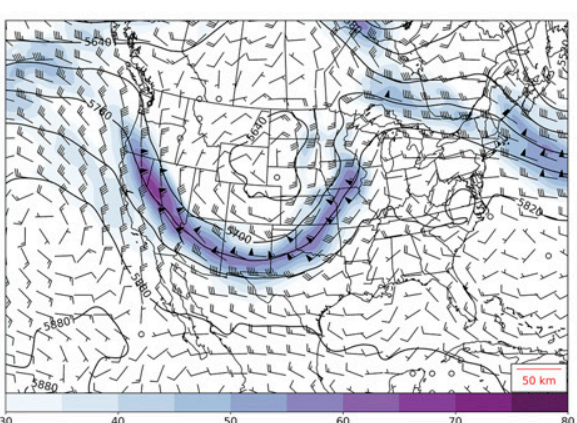

(a)

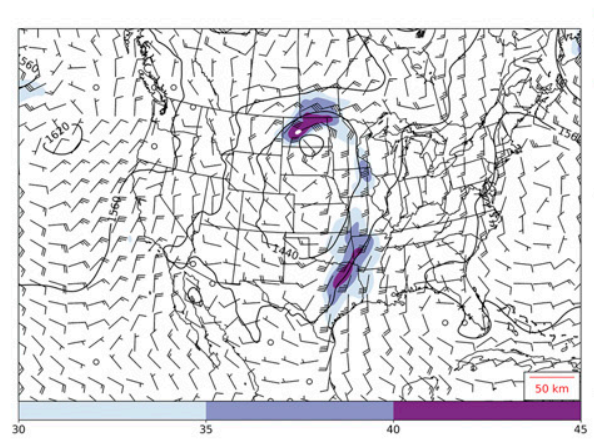

(c)

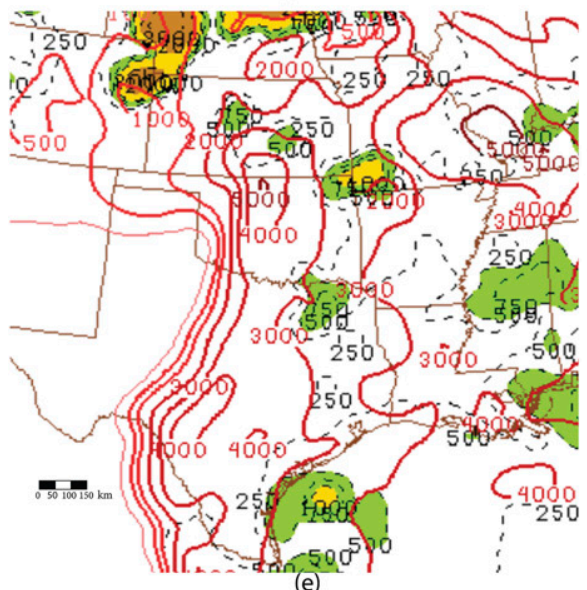

(e)

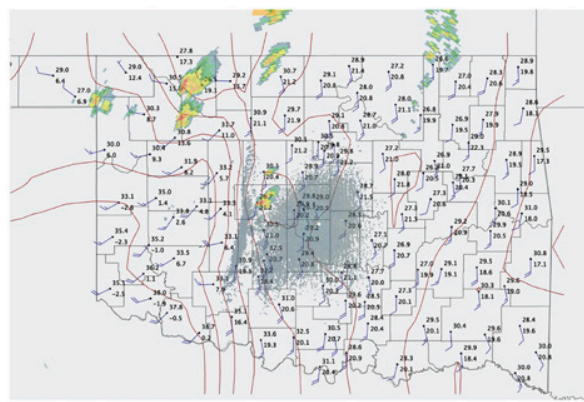

(g)

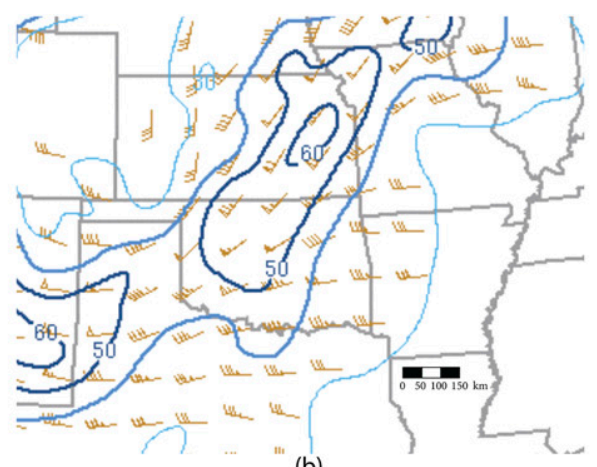

(b)

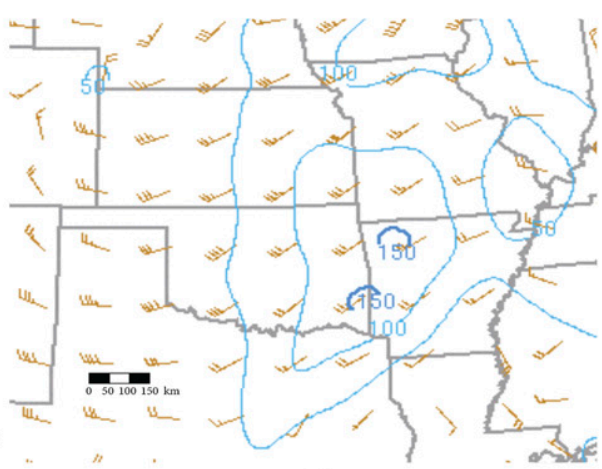

(d)

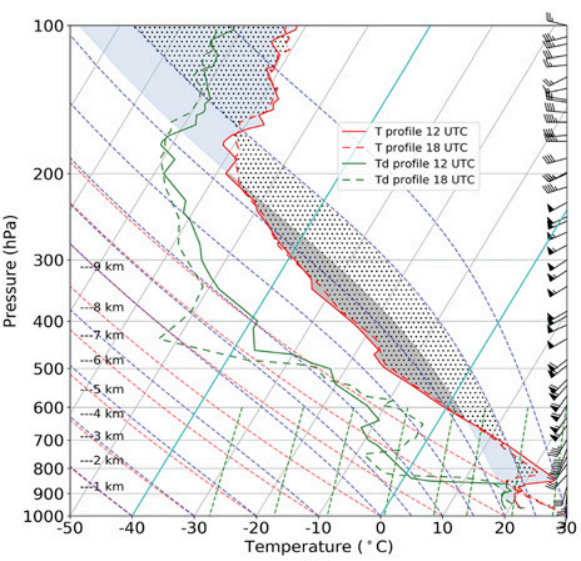

(f)

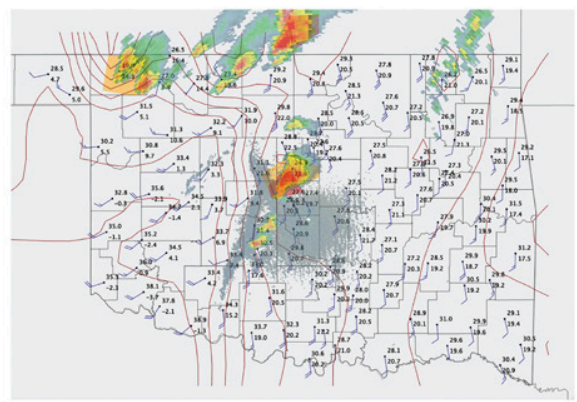

(h)

FIG. 1. Summary of synoptic and mesoscale environment on 19 May 2013. (a) 500-hPa geopotential heights (m) and wind speeds (kt) at 1800 UTC from the operational North American Mesoscale model run initialized at 1800 UTC. (b) As in (a), but at $850 \mathrm{hPa}$. (c) NWS Storm Prediction Center mesoanalysis of 0-6 km AGL bulk wind shear at 2100 UTC. (d) As in (c), but for $0-1-\mathrm{km}$ storm relative helicity $\left(\mathrm{m}^{2} \mathrm{~s}^{-2}\right)$. (e) Mesoanalysis of most unstable CAPE at 1800 UTC. 
progressed (Fig. 1f). However, there was still some evidence of an elevated mixed layer at 1800 UTC $(1.5-2.5 \mathrm{~km}$ AGL), due to relatively dry air transported over the Rockies. The 1800 UTC sounding from Norman, Oklahoma (Fig. 1f) also showed a moist layer extending above $850 \mathrm{hPa}$, and steep midlevel lapse rates exceeding $8^{\circ} \mathrm{C} \mathrm{km}^{-1}$ in the 825-500-hPa layer. Around the same time, a dryline (visible as a gradient in relative humidity contours, Figs. $1 \mathrm{~g}, \mathrm{~h}$ ), attendant to a deepening surface low over northwestern Oklahoma, was rapidly mixing eastward across western Oklahoma while dewpoint temperatures over central Oklahoma were near $20^{\circ} \mathrm{C}$.

The storm of greatest interest in this study will hereafter be called "the Edmond-Carney supercell," in reference to the two Oklahoma cities that experienced its greatest impacts. The Edmond-Carney supercell initiated around 2000 UTC near El Reno, Oklahoma, within the region of persistent convergence along the dryline, and moved eastward into central Oklahoma along with it (Figs. 1g,h). It quickly matured and started producing severe weather (hail and strong winds) around 2030 UTC (refer SPC 2013). The storm remained isolated and north of other storms that initiated later, farther southwest along the dryline near Norman and Shawnee, Oklahoma. The EdmondCarney supercell exhibited cyclic intensification and weakening of core updraft pulse (not shown). As the storm approached Edmond, Oklahoma, it produced a tornado with a damage rating of 0 on the enhanced Fujita (EF) scale (McDonald and Mehta 2006) around 2122 UTC. The storm produced at least two additional EF1 tornadoes: one at 2133 UTC near Arcadia, Oklahoma, and the other at 2153 UTC near Fallis, Oklahoma. The most intense tornado from this supercell began just south of Carney, Oklahoma, around 2213 UTC, and inflicted EF3 damage as it passed over sections of Carney. There is some discrepancy between the timing and number of tornado reports from multiple sources (e.g., the database on NWS Norman web page (available at https:/www.weather.gov/oun/ events-20130519-tornadotable) mentions only three tornado reports compared to four from SPC storm reports database and five from NCEI storm events database). Nevertheless, this discrepancy does not change our interpretations in any major way.

\section{Data and methodology}

\section{a. Instrumentation details}

A major reason for choosing this particular case for our study was the availability of high-quality polarimetric radar and 3D very high frequency (VHF) lightning observational data. For its entire life cycle, the Edmond-Carney supercell remained within the sampling range of KTLX radar (WSR88D located at Twin Lakes, Oklahoma) and the Oklahoma
Lightning Mapping Array (OKLMA) (Fig. 2a). Radar data included level II products: reflectivity $Z$, differential reflectivity $Z_{\mathrm{DR}}$, cross-correlation coefficient $\rho_{\mathrm{hv}}$, radial velocity $V_{r}$, and differential phase $\Phi_{\mathrm{DP}}$. KTLX collected PPI (plan position indicator) scans while operating in "precipitation mode." Volume coverage pattern (VCP) 12 (Office of the Federal Coordinator for Meteorology 2016) consists of 15 elevation angles between $0.5^{\circ}$ and $19.5^{\circ}$, with most scans concentrated in the lowest $5^{\circ}$, and volume updates every $\sim 4-5 \mathrm{~min}$. VHF lightning source data for this case were collected by the OKLMA network (Thomas et al. 2004; MacGorman et al. 2008). The lightning channel emits impulsive radiation during propagation in the $60-66-\mathrm{MHz}$ VHF band. OKLMA sensors detect the three-dimensional structure of a lightning flash via triangulation. A total of 15 sensors out of 18 were active for the period of interest (2000-2300 UTC 19 May 2013). However, at least four stations had marginal percentage contribution to the number of sources detected throughout. CG lightning data used in this study were obtained from the National Lightning Detection Network (NLDN) operated by Vaisala Inc., which consists of over 100 sensors spread across the United States (Cummins et al. 1998; Orville 2008; Nag et al. 2014).

\section{b. Data processing and analysis methods}

\section{1) VHF SOURCE DATA FROM OKLMA}

VHF mapping of lightning flashes permits estimating (i) the path traversed by an individual flash, and (ii) the charge through which it moved (Rison et al. 1999). A lightning discharge propagates as a bidirectional leader with the negative leader (carrying negative charge) propagating toward region of positive charge and vice versa (Williams et al. 1985; Mansell et al. 2002; Coleman et al. 2003; Wiens et al. 2005). We use this model to infer charge regions from the spatiotemporal evolution of individual lightning flashes in the storm (Kasemir 1960; MacGorman et al. 2008). Rison et al. (1999) described that the radio signal emanated by negative leaders tends to be noisier than their positive counterpart resulting in more accurate and precise mapping of negative breakdown process. Thus, a negative leader propagating through a positive charge layer would map out its distribution and location. Although positive leaders are quieter, resulting in sometimes poor mapping of negative charge layer, those regions still get detected when negative leaders retrace the path of positive leaders corresponding to recoil streamer activity (Mazur and Ruhnke 1993). VHF sources for all individual flashes in the Edmond-Carney storm were manually isolated to perform charge classification using XLMA software (Rison et al. 1999, ftp://zeus.nmt.edu/thomas, accessed June 2018). A total of approximately $33 \mathrm{~min}$ of flash data (2110-2120,

(f) Skew $T-\log p$ plots of soundings launched at 1200 and 1800 UTC from NWS Norman, OK, WFO on 19 May 2013. CAPE and CIN for 1200 UTC sounding are shaded in gray and blue, respectively, while the same parameters are hatched for the 1800 UTC sounding. (g) Mesonet station plot of the surface temperature $\left({ }^{\circ} \mathrm{C}\right)$, dewpoint temperature $\left({ }^{\circ} \mathrm{C}\right)$, and winds $\left(\mathrm{m} \mathrm{s}^{-1}\right)$ across OK at $2000 \mathrm{UTC}$ 19 May 2013. (h) As in (g), but at 2100 UTC. Contours of relative humidity, base reflectivity, and severe and tornado warning polygons are overlaid for reference. 


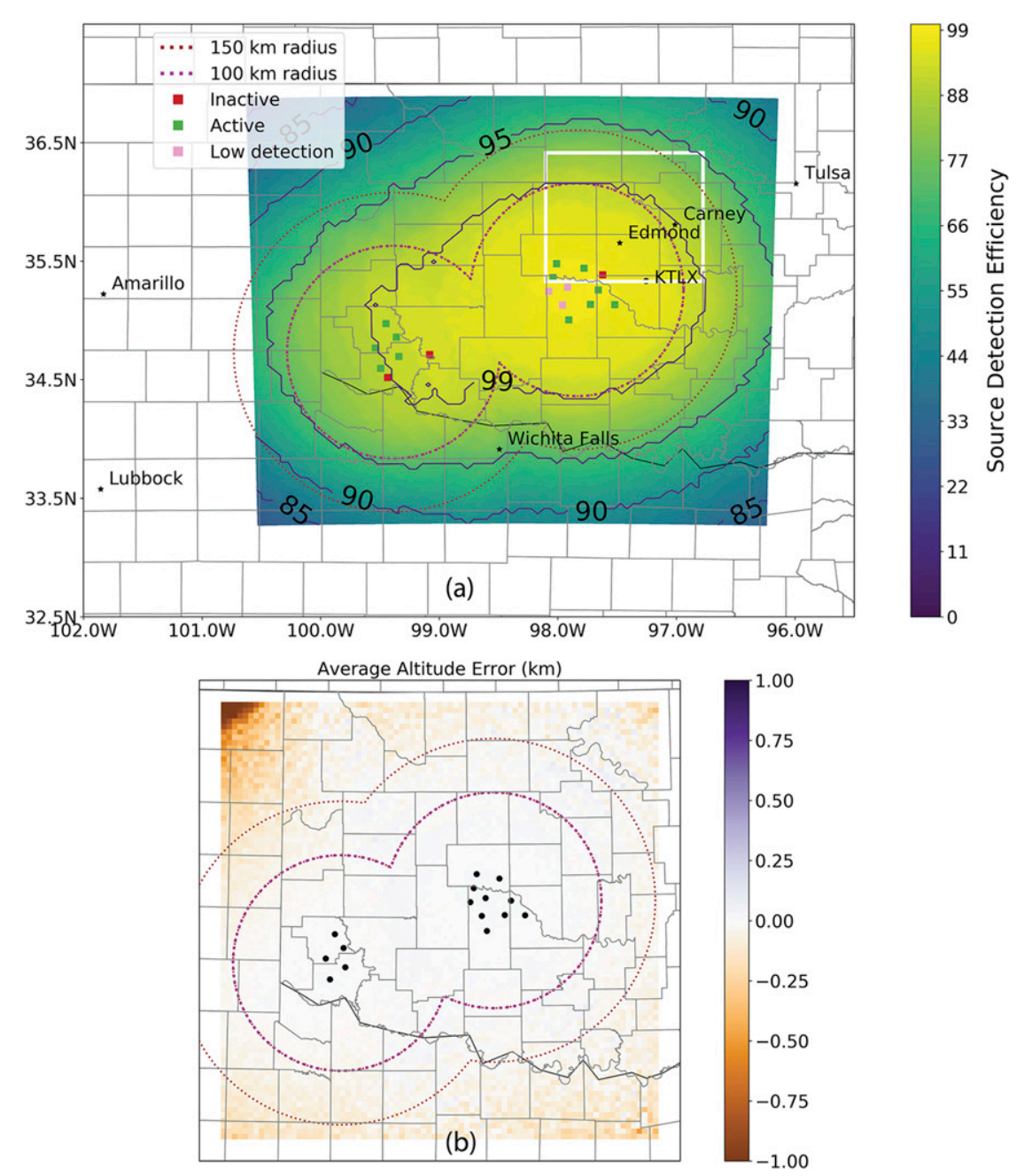

FIG. 2. (a) OKLMA source detection efficiency (shaded) overlaid with flash detection efficiency (black contour lines; percentage) and location of individual stations and KTLX radar. The white rectangular box is the domain of analysis for this study. (b) Average difference in altitude $(\mathrm{km})$ from the center of OKLMA network representing vertical location error of VHF sources. Dotted lines in both (a) and (b) indicate the 150- and 100-km range rings around each LMA center. Note that flash detection efficiency $>95 \%$ and magnitude of average error in source altitude $<0.25 \mathrm{~km}$ within $150-\mathrm{km}$ radius, including the analysis domain.

2120-2123, 2130-2140, and 2140-2150 UTC) were classified as positive and negative leaders using a combination of reduced $\chi^{2}$ value $\leq 5$ with at least six stations contributing data. The result was sufficient to assess the three-dimensional, timeevolving charge structure.

The same approach as Chmielewski and Bruning (2016) was used to characterize the performance of OKLMA with only 11 stations contributing actively to VHF source detection. We found that at least $95 \%$ of flashes with at least $80 \%$ source detection efficiency can be resolved within our analysis domain (white box in Fig. 2a). The average altitude error for VHF sources was found to be less than $250 \mathrm{~m}$ (Fig. 2b). Postprocessing of LMA data were performed using lmatools python package (version 0.5) (deeplycloudy 2015; Fuchs et al. 2016, downloaded from https://github.com/deeplycloudy/lmatools, last accessed
January 2020). At its core, lmatools uses the DBSCAN algorithm (Ester et al. 1996) to classify a cluster of points into an individual lightning flash. Ten or more VHF sources were classified as a lightning flash when all contributing sources occurred within a distance of $3 \mathrm{~km}$ and a time window of $150 \mathrm{~ms}$ from the first identified source in that flash (MacGorman et al. 2008; Bruning and MacGorman 2013). Further processing uses the flash and source information to produce fields such as flash extent density, flash initiation density, and source density (Bruning and MacGorman 2013) in two and three-dimensional grids. The grid size and spacing in horizontal $(500 \mathrm{~m} \times 500 \mathrm{~m})$ was identical with the Cartesian grid for objective analysis of radar data as explained in section 3. A vertical grid spacing of $500 \mathrm{~m}$ was deemed satisfactory since the average altitude error for VHF sources was found to be less than $250 \mathrm{~m}$. The two grids 
differed in the vertical extent ( $20 \mathrm{~km}$ for flash grids versus $15 \mathrm{~km}$ for radar) because upper portions of the storm could not be sampled in the cone of silence region whereas LMA sensors recorded VHF sources at those altitudes.

\section{2) CG FLASH ANALYSIS}

While analyzing NLDN CG flash data, an absolute value of $15 \mathrm{kA}$ for peak current threshold was used to exclude intracloud (IC) flashes that may have been misclassified as CG flashes by the NLDN (Biagi et al. 2007). Previous researchers have used a lower threshold of $10 \mathrm{kA}$ (Johnson and Mansell 2006), but we found the 15-kA threshold to filter out most (though as we show later, not all) of the ambiguous flashes with low peak current values which are generally IC flashes misreported as CG flashes in the data (Cummins and Murphy 2009; Fleenor et al. 2009). Moreover, Murphy et al. (2021) discuss issues with the upgraded, more sensitive NLDN hardware combined with an old classification algorithm which also probably contributed additional classification uncertainty.

\section{3) RADAR DATA OBJECTIVE ANALYSIS}

Quantification of geometric properties of polarimetric signatures involves objective analysis of WSR-88D level-II data onto a uniform grid. Gridding of radar observations (which are typically collected in radar-centered spherical coordinates) using objective analysis techniques can lead to spurious artifacts if parameters are not chosen carefully (Carbone et al. 1985; Trapp and Doswell 2000). Moreover, due to inherent instrument noise in level-II moment data, we also performed additional quality checks to avoid the effect of such noise getting mixed with weather signals during the smoothing operation in the gridding process (Askelson et al. 2000). In this study, we were interested in the volumetric analysis of $Z_{\mathrm{DR}}$ and $K_{\mathrm{DP}}$ columns; therefore, we gridded only the $Z_{\mathrm{DR}}$ and $K_{\mathrm{DP}}$ fields.

First, the $Z_{\mathrm{DR}}$ observations were despeckled i.e., small objects identified as nonmeteorological artifacts were masked out from each radar volume scan. Second, $Z_{\mathrm{DR}}$ observations at gates where the value of $\rho_{\mathrm{hv}}<0.8$ and $Z<20 \mathrm{~dB} Z$ were masked, in order to remove nonmeteorological clutter and other noise in the data (Ryzhkov and Zrnić 1998). The final step involved gridding each radar volume to a $3 \mathrm{D}$ Cartesian grid of size $120 \mathrm{~km} \times 120 \mathrm{~km} \times 15 \mathrm{~km}$ and grid cell size of $500 \mathrm{~m} \times 500 \mathrm{~m} \times$ $500 \mathrm{~m}$ in the $x, y$, and $z$ directions, respectively. We used a singlepass Barnes objective analysis scheme (Barnes 1964; Majcen et al. 2008) with a constant radius of influence (ROI) of $1149 \mathrm{~m}$ calculated via the method described by Kosiba et al. (2013).

Level-II WSR-88D data files do not include the $K_{\mathrm{DP}}$ field, and level-III WSR-88D files only contain the $K_{\mathrm{DP}}$ field at the lowest four tilts. Therefore, we used the linear programming algorithm described in Giangrande et al. (2013) to generate the differential phase field for the entire level-II volume. The $K_{\mathrm{DP}}$ cannot be reliably estimated in areas of low $\rho_{\text {hv }}$ (below 0.8-0.9) (Ryzhkov and Zrnić 2019). Therefore, we masked all range gates with $\rho_{\mathrm{hv}}<0.8$ prior to retrieval of the $K_{\mathrm{DP}}$ field. A detailed list of parameter values used for $K_{\mathrm{DP}}$ retrieval can be found in Table A1.

As a final step, only grid points with values greater than $1 \mathrm{~dB}$ and $0.75^{\circ} \mathrm{km}^{-1}$ were considered for identification of $Z_{\mathrm{DR}}$ and
$K_{\mathrm{DP}}$ columns, respectively. Subsequently the masked grid data for each of these fields, in 31 horizontal slices of 500-m depth, were saved as raster images which in turn were used as input for the object identification algorithm described below.

High $Z_{\mathrm{DR}}$ and $K_{\mathrm{DP}}$ above the $0^{\circ} \mathrm{C}$ level indicate the presence of water associated with either supercooled raindrops, raindrops in the process of freezing, or water-coated hail growing in a wet growth regime (Ryzhkov and Zrnić 2019). This was the basis for identifying and isolating $Z_{\mathrm{DR}}$ and $K_{\mathrm{DP}}$ columns in our gridded dataset. We used a $3 \mathrm{D}$ segmentation tool to isolate $Z_{\mathrm{DR}}$ and $K_{\mathrm{DP}}$ column objects for each radar volume and at each $z$-level using the "aics-segmentation" package for Python (Chen et al. 2018, version 0.1.16.dev4, https://github.com/ AllenInstitute/aics-segmentation, accessed January 2020). The segmentation technique for $Z_{\mathrm{DR}}$ or $K_{\mathrm{DP}}$ column object identification comprises the following three steps:

- Step 1: Preprocessing-Automatic contrast normalization was applied to suppress extremely low/high pixel intensity values in the input image slices containing $Z_{\mathrm{DR}}$ and $K_{\mathrm{DP}}$ field data. To achieve this, the mean $\hat{\mu}$ and standard deviation $\hat{\sigma}$ of pixel intensity was first estimated by fitting a Gaussian distribution to the intensity profile $I$ of all pixels composing the gridded volume for each radar scan [Eq. (A1)]. Next, the original intensity range was transformed to the range [mean $a \times \mathrm{std}$, mean $+b \times \mathrm{std}]\left[I^{\prime}\right.$ in Eq. (A2)], and then normalized to the range $[0,1]\left[I_{N}\right.$ in Eq. (A3)]. Additionally, 2D Gaussian smoothing was performed on intensity values at each horizontal slice $I_{N}^{i}$ to obtain the smoothed intensity values $\left(I_{S}\right)$ as shown in Eqs. (A4) and (A5).

- Step 2: Core segmentation algorithm-The images produced in step 1 (with normalized pixel intensity) were filtered using a sequence of 2D and 3D filament and spot filters as described in Chen et al. (2018). A watershed algorithm was then used to segment regions with local maximum pixel intensity into objects with unique identifiers.

- Step 3: Postprocessing-To refine the results from the segmentation process in step 2, we used a morphological holefilling algorithm to fill in interior holes in identified features (chapter 6, Soille 2004). Last, a size filter was used as a threshold to remove features with unreasonably small or large areas.

The final output of the AICS segmentation for each radar volume was a set of objectively identified three-dimensional $Z_{\mathrm{DR}}$ and $K_{\mathrm{DP}}$ column objects for each scan volume. All detected objects were assigned an identification label during postprocessing. Quantitative geometrics, such as column height and volume, were computed for each object. To calculate the height of individual objects, the horizontal crosssectional area (in $\mathrm{km}^{2}$ ) of each object was calculated at all levels starting from the $0^{\circ} \mathrm{C}$ level. The top of the column object was defined as that height at which the column area decreased below $1 \mathrm{~km}^{2}$. The column height was obtained by multiplying the number of levels between the melting level and column top by $500 \mathrm{~m}$ (i.e., the vertical grid spacing). Volume was calculated by counting the total number of grid points (exceeding respective thresholds) within the bounding box of each $Z_{\mathrm{DR}}$ or $K_{\mathrm{DP}}$ object. Finally, volume at each level 

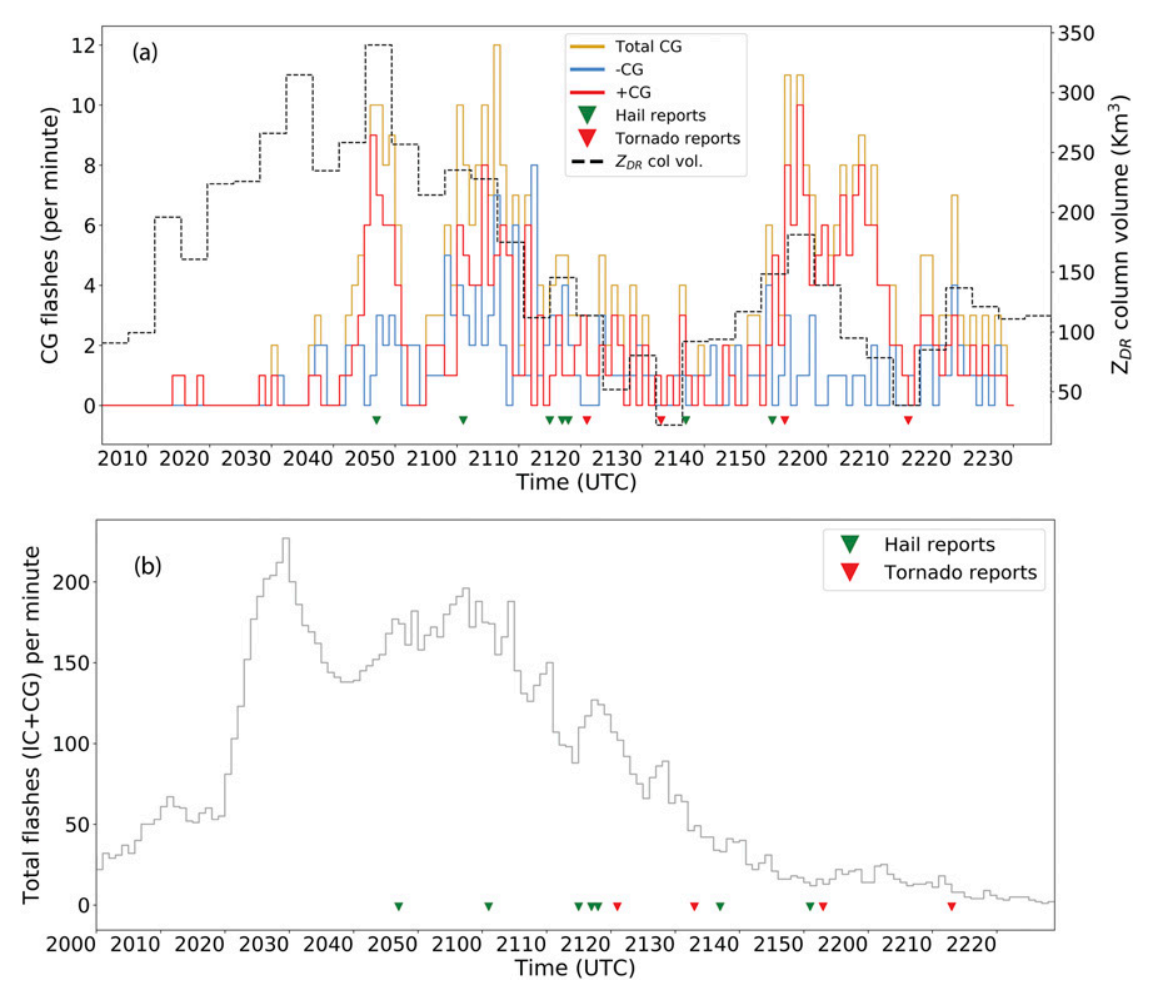

FIG. 3. (a) CG flash rates calculated using NLDN data. + CG flash rates are plotted in red, -CG flash rates are plotted in blue, and total CG flash rates are plotted in yellow. Only those flashes with peak current magnitude greater than $15 \mathrm{kA}$ were used to calculate flash rates to avoid any errors due to IC flashes misclassified as CG flashes in the NLDN database. Red (green) triangular markers indicate tornado (hail) reports. The $Z_{\mathrm{DR}}$ column volume is overlaid in a black dashed line. (b) Total flash rates (IC + CG) calculated from data collected using Oklahoma Lightning Mapping Array (OKLMA).

was computed by multiplying the number of grid points at that level with the volume of a single grid cell $(500 \mathrm{~m} \times$ $500 \mathrm{~m} \times 500 \mathrm{~m})$.

\section{Results and discussion}

\section{a. Flash rates and polarity}

$\mathrm{CG}$ and total (IC + CG) flash rates observed in the Edmond-Carney storm, with peak values of 200 and 12 flashes per minute, respectively (Fig. 3), are comparable with those reported in several past studies [cf. Table 4.1 in Betz et al. (2008)]. The first few CG flashes in the storm were positive in polarity (hereafter, $+\mathrm{CG}$ ). It is evident that negative $\mathrm{CG}$ (hereafter, $-\mathrm{CG}$ ) flash activity began at least $15 \mathrm{~min}$ after the first CG flashes, by which time total lightning flash rates had already reached values around 200 flashes per minute (Fig. 3b). Thus, the majority of lightning activity in the first 30 min of our analysis can be attributed to IC flashes.

\section{1) Predominantly positive CG (PPCG) Storms}

$65 \%$ of the CG flashes in the storm had a positive polarity, so the storm fits the definition of a PPCG storm. In contrast to some studies (Curran and Rust 1992; MacGorman and Burgess 1994; Bluestein and MacGorman 1998; Carey and Rutledge
1998) that reported CG polarity reversal after tornadogenesis or during a transition in supercell morphology, the EdmondCarney storm was dominated by $+\mathrm{CG}$ flashes throughout its lifetime. However, there was at least one phase in its lifetime when $-\mathrm{CG}$ flash rates were comparable to $+\mathrm{CG}$ flash rates (between $\sim 2100$ and 2130 UTC; refer Figs. 3a and 10a). We looked closely at the LMA data between 2113 and 2114 UTC, when eight - CGs ranging from -15 to $-25 \mathrm{kA}$ peak current were reported. Each flash had extensive horizontal propagation of negative leaders at altitudes between 5 and $7 \mathrm{~km}$ MSL, and no downward propagation below $5 \mathrm{~km}$. Some strokes aligned with initial breakdown. The LMA observations are consistent with past examples of misclassified -CGs (Zhu et al. 2016). Therefore, we suspect that the storm had an even higher percentage of $+\mathrm{CG}$ flashes than the initial results indicate.

A positive correlation between $+\mathrm{CG}$ flash rates and $Z_{\mathrm{DR}}$ column volume is evident in Fig. 3a, wherein the largest increases in $+\mathrm{CG}$ flash rates were found to follow the peaks in $Z_{\mathrm{DR}}$ column volume. This behavior is consistent with the findings of Lang and Rutledge (2002) and Carey et al. (2003) as they found that upward pulses in updraft volume preceded a steady increase in + CG flash rates. They hypothesized that larger updraft volume (defined as having vertical wind 

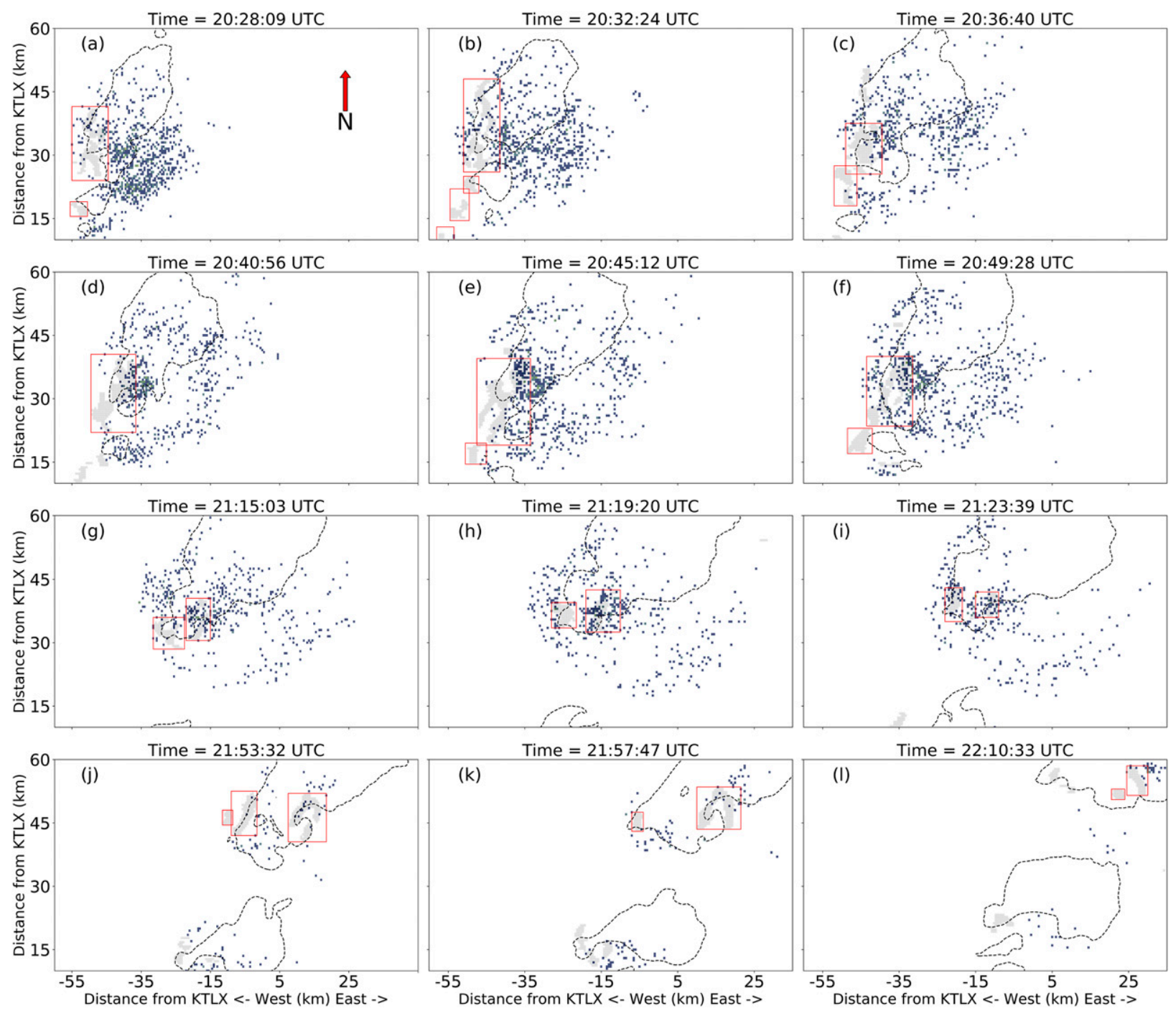

FIG. 4. Flash initiation density within a $500 \mathrm{~m} \times 500 \mathrm{~m} \times 500 \mathrm{~m}$ grid with its origin at KTLX, plotted for time intervals corresponding to KTLX volume scans whose start times are given in UTC at the top of each panel. The $Z_{\mathrm{DR}}$ column objects identified from $3 \mathrm{D}$ segmentation algorithm are overlaid in red bounding boxes for reference. The $30-\mathrm{dB} Z$ reflectivity contour at 2 -km altitude is shown in the dotted black line.

speed $>20 \mathrm{~m} \mathrm{~s}^{-1}$ ) imparts more moisture to hydrometeors as it lifts them to higher altitudes, thereby enabling frequent collisions of ice particles to enhance net charge density.

\section{2) CG FLASH RATES AND TORNADOGENESIS}

Increased $+\mathrm{CG}$ activity in the Edmond-Carney storm was observed only during the time of one of the tornado reports at 2153 UTC (Fig. 3a). The most intense (EF3) tornado was reported near Carney, Oklahoma, at 2213 UTC, which is just after the $+\mathrm{CG}$ flash rates peaked. However, the tornado reports at 2121 and 2133 UTC defy this trend. Both of those reports lie within the period of lowest $+\mathrm{CG}$ flash rates (as well as total flash rates). Steiger et al. (2007) documented a similar pattern in their analysis of flash rates in a Texas supercell wherein CG flash rates were locally minimized during an ongoing tornado. On the other hand, a number of studies have found contrasting results such as tornadogenesis during and after peak + CG flash rates (MacGorman and Burgess 1994), and a dramatic increase in $+\mathrm{CG}$ flashes after tornadogenesis (Carey et al. 2003). To summarize, CG lightning behavior in the Edmond-Carney supercell exhibited a combination of sometimes opposing behaviors seen in different supercell thunderstorms analyzed in the past studies. We take this result as further evidence against a consistent relationship between cloud-to-ground lightning behavior and tornadogenesis in supercells.

Most tornado reports from the storm correspond to the time of reduced $Z_{\mathrm{DR}}$ column volume with the only exception at 2153 UTC when $Z_{\mathrm{DR}}$ column volume and $+\mathrm{CG}$ flash rates were relatively large (Fig. 3a). It is possible that the reduced volume was a manifestation of weakening of midlevel updrafts as a result of downward directed pressure perturbation due to 

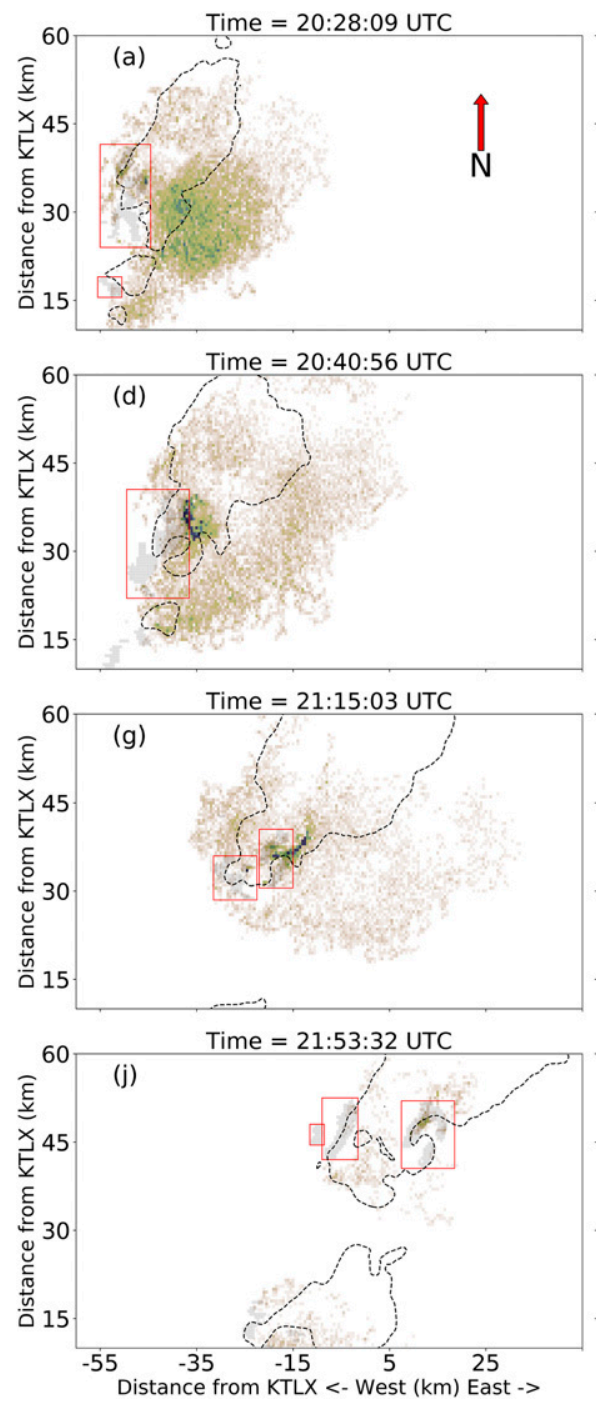
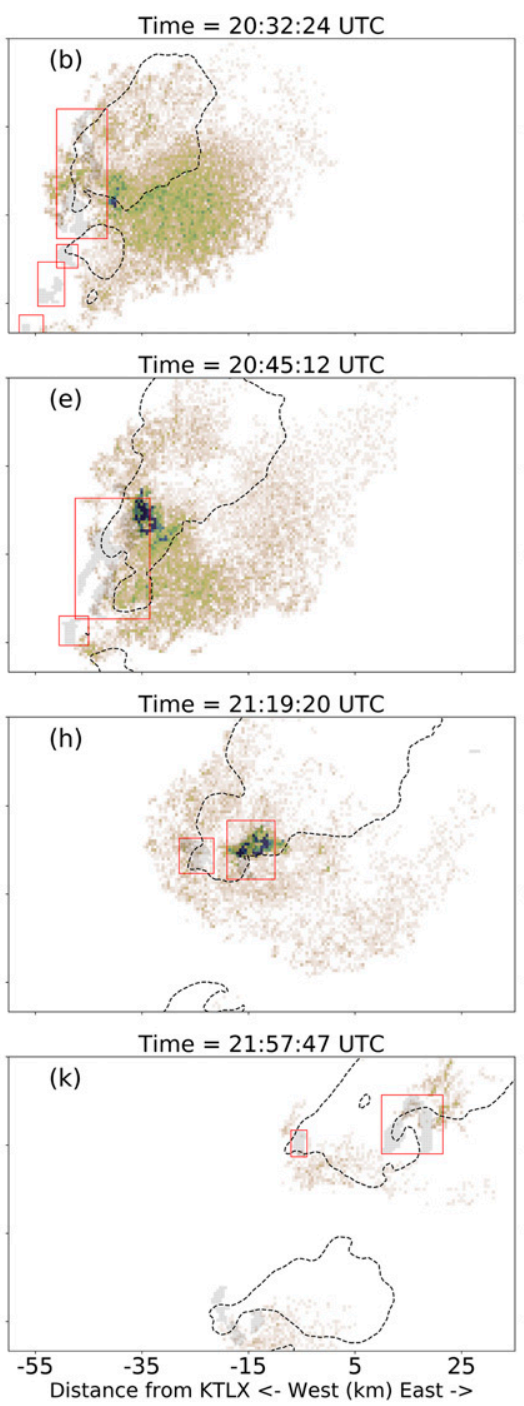
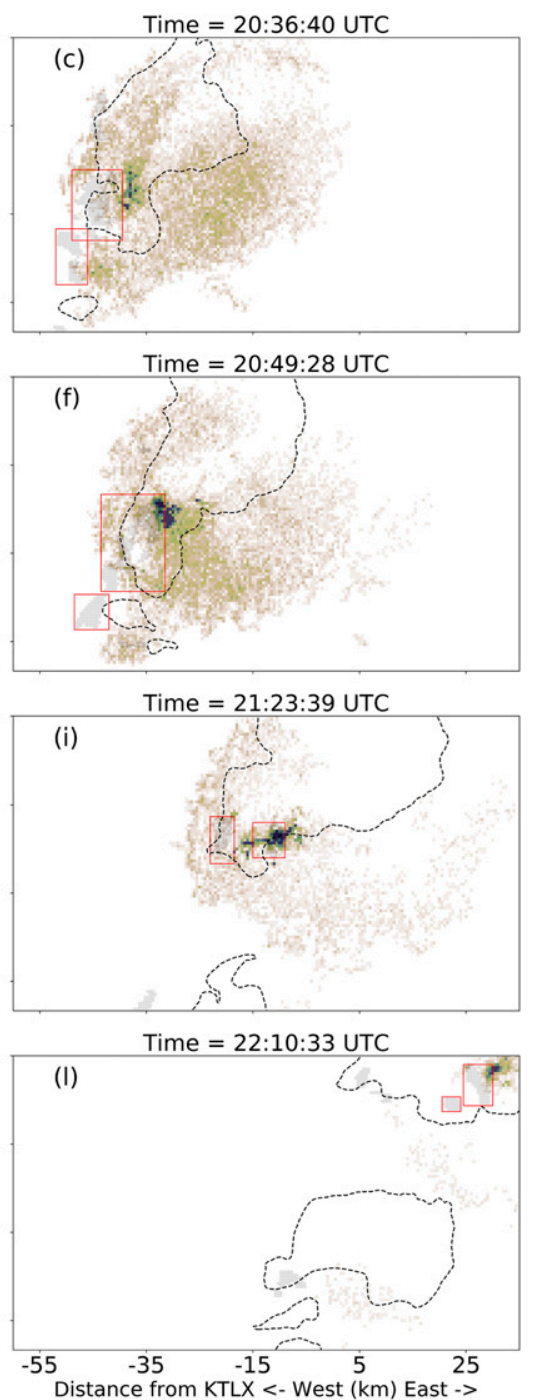

FIG. 5. Flash source density during significant phases in the Edmond-Carney storm's life cycle: (a)-(c) during maximum lightning flash rates, (d)-(f) during the shift in source density maximum from south to north toward the $Z_{\mathrm{DR}}$ column objects, (g)-(i) during the first tornado report at $2122 \mathrm{UTC}$, and (j)-(l) during the third tornado report at $2153 \mathrm{UTC}$. The $30-\mathrm{dBZ}$ reflectivity contour at $2-\mathrm{km}$ altitude is shown in the dotted black line.

strengthening of low-level mesocyclone (Brandes 1978; Lemon and Doswell 1979; Trapp 1999). As per the NLDN flash rates, a lightning jump occurred at 2156 UTC just 3 min after 2153 UTC tornado report linked with increasing $+C G$ flash rates and $Z_{\mathrm{DR}}$ column volume. Thus, tracking the evolution of $Z_{\mathrm{DR}}$ column volume alone may not conclusively inform forecasters to issue tornado warnings.

\section{3) INVERSE RELATIONSHIP BETWEEN FLASH INITIATIONS AND CHANNEL EXTENT LENGTH}

Juxtaposition of gridded flash products with $Z_{\mathrm{DR}}$ columns reveals evolution of the most active electrical regions throughout the storm lifetime (Figs. 4-6). Figure 7 orients low-level (contours) and midlevel (shaded) reflectivity data relative to lightning activity corresponding to each of the plots in Figs. 4-6. Panels (a)-(c) in each figure depict storm evolution between
2028 and 2036 UTC, corresponding to the time period of maximum total lightning flash rates (cf. Fig. 3b). During this period, flash initiation density was highest $(\sim 6-7$ flash initiations per minute per grid point) in the region southeast of the $30-\mathrm{dB} Z$ contour. All $Z_{\mathrm{DR}}$ columns were located to the northwest of those maximum initiation values. However, the mean flash size in the region of $Z_{\mathrm{DR}}$ columns was the smallest with larger flashes confined to the main forward flank region (Fig. 6).

Flash source density maximum made a noticeable shift toward the $Z_{\mathrm{DR}}$ column objects between 2040 and 2049 UTC (Figs. 5d-f). One possible reason for this shift could be the development of mesocyclone and subsequent consolidation of mesoscale updraft, leading to a large updraft-downdraft interface (cf. Fig. 8a). The larger interface could have enabled higher ice particle concentration, increased vertical mass flux of small charged ice particles in the mixed-phase 

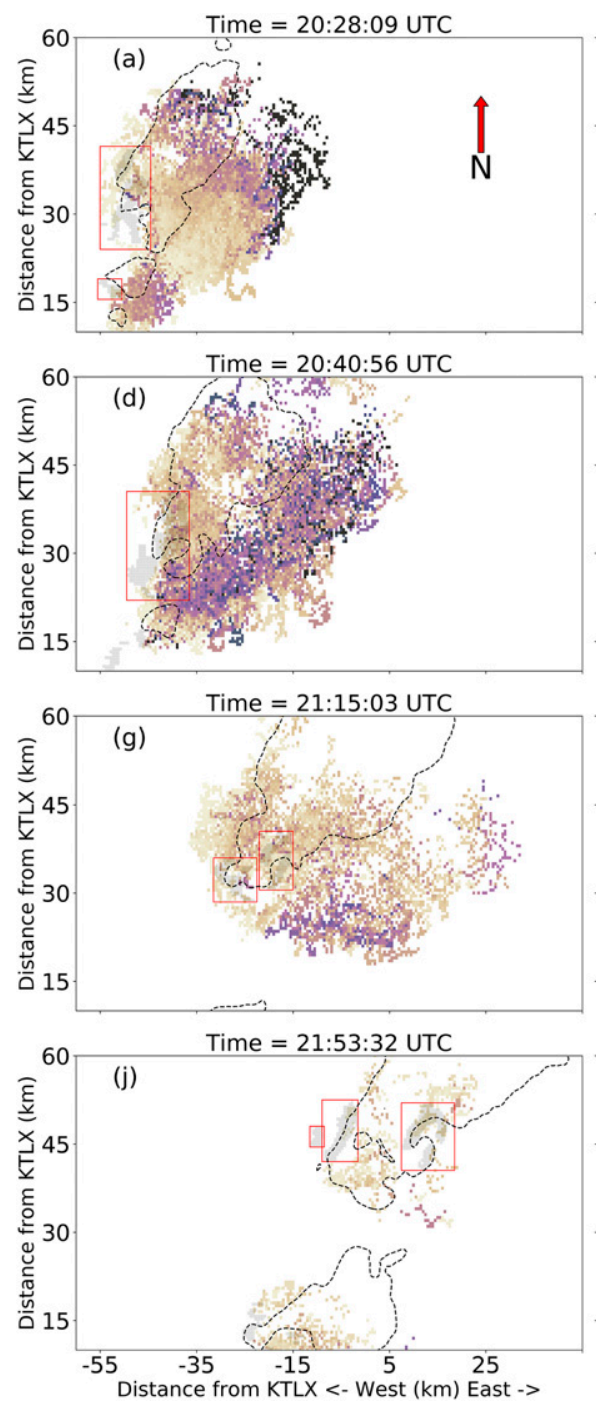

FIG. 6. As in Fig. 4, but for mean flash area.
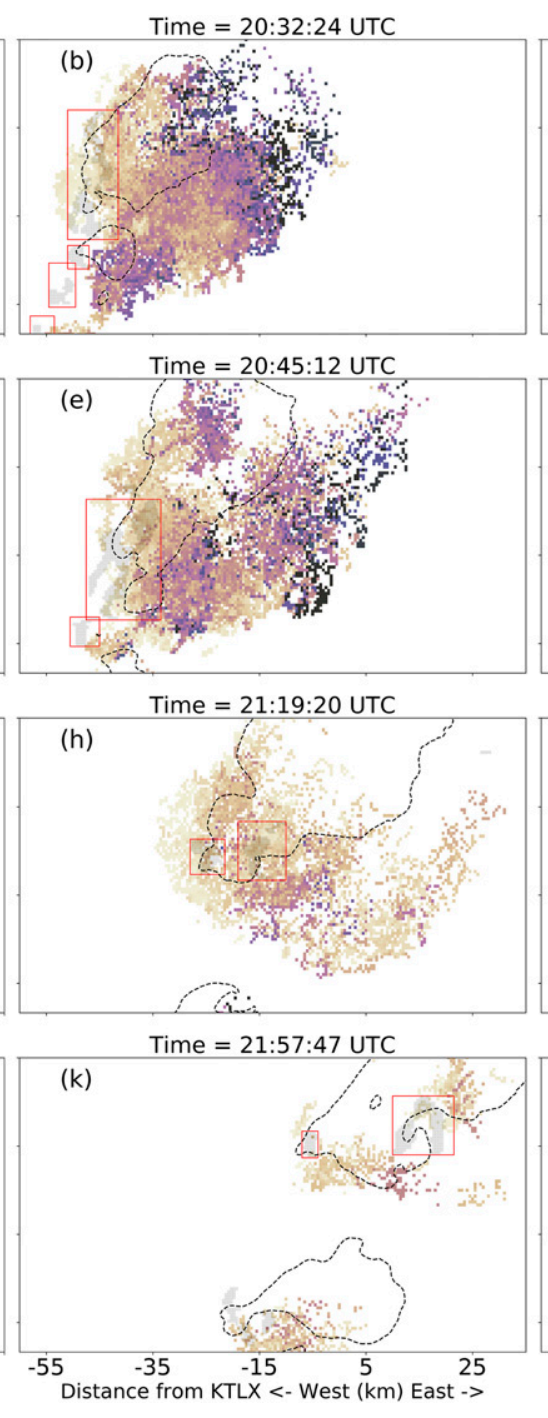
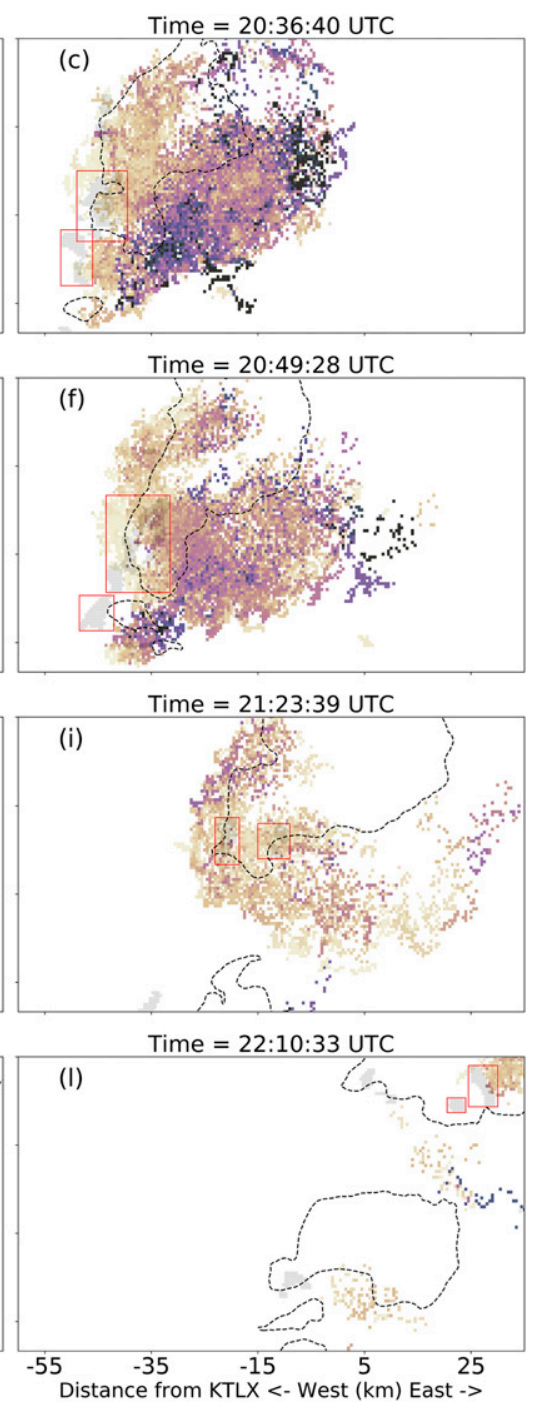

region, and active charge separation as reported in Schultz et al. (2015).

When the first tornado was reported ( 2122 UTC), maximum initiation density was confined within the bounding region of $Z_{\mathrm{DR}}$ columns, but the overall extent of the flash footprint was evenly spread over northern and southern flanks of the storm [panels (g)-(i) in Figs. 4 and 6]. The mean flash size within this region of maximum initiation still remained small, with larger flashes occurring mostly in the southern flank. The near-perfect alignment between $Z_{\mathrm{DR}}$ column and the maximum lightning source density could also mean that the storm had developed a steady updraft by 2115 UTC. Although the flash rates decreased considerably during the last reported tornado ( 2213 UTC, Figs. 6j-1), their inverse relationship with flash size was still valid.

To further consolidate our claim, we separated grid points within and outside the region bounded by $Z_{\mathrm{DR}}$ columns for each radar volume scan. The mean flash area and the total count of flash initiations were then calculated for each region at each time step. A significant difference was found between flash initiations within and outside $Z_{\mathrm{DR}}$ column regions using the Wilcoxon rank-sum test ( $p<0.05$; Fig. 9). On average, there were 5 times more initiations inside the $Z_{\mathrm{DR}}$ column region compared to outside (Hedges's $g=1.08$; see Cumming (2013) for details on effect size). On the other hand, mean flash size (in $\mathrm{km}^{2}$ ) within the $Z_{\mathrm{DR}}$ column region was $\sim \mathcal{O}(10)$ smaller than outside (again, $p<0.05$ ). Hedges's $g$ was found to be 0.86 for this case. In other words, flashes within $Z_{\mathrm{DR}}$ columns (proxy for updrafts) were smaller and more frequent compared to rest of the storm, thereby verifying the flash initiation and propagation theory (Calhoun et al. 2013; Bruning and MacGorman 2013). Rapid sampling of $Z_{\mathrm{DR}}$ columns (i.e., volume update times $\sim 1-2 \mathrm{~min}$ ) will likely provide adequate temporal resolution to capture fluctuations in updraft intensity to correlate with transient lightning characteristics like lightning jumps and lightning dives. 


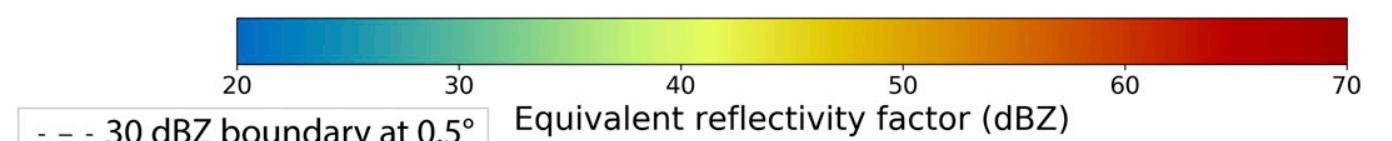

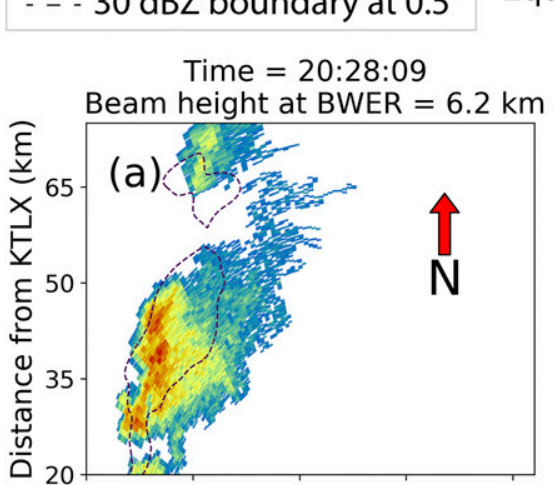

Time $=20: 40: 56$

Beam height at BWER $=7.0 \mathrm{~km}$

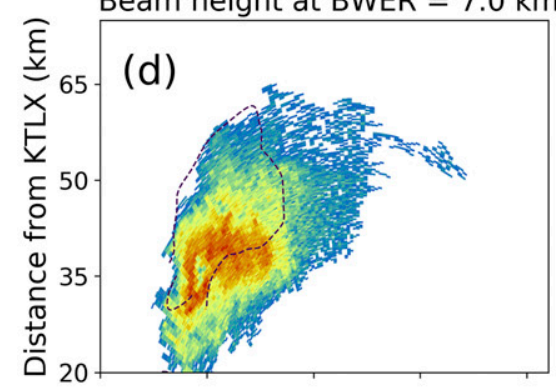

Time $=21: 15: 03$

Beam height at BWER $=5.4 \mathrm{~km}$

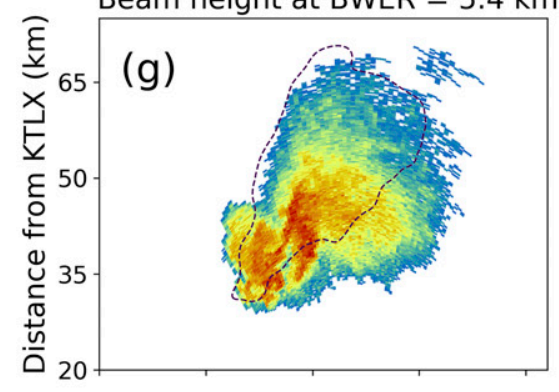

Time $=21: 53: 32$

Beam height at BWER $=4.4 \mathrm{~km}$

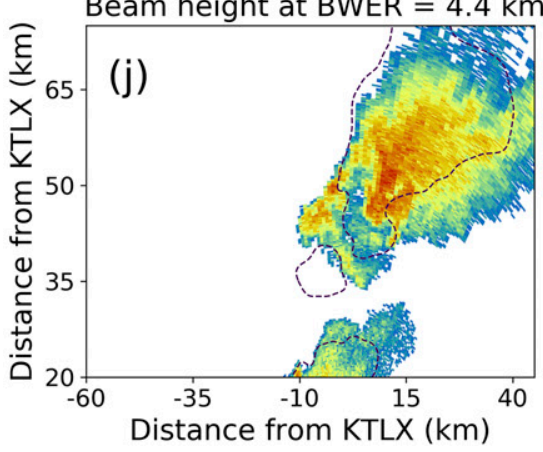

Time $=20: 32: 24$

Beam height at BWER $=6.2 \mathrm{~km}$

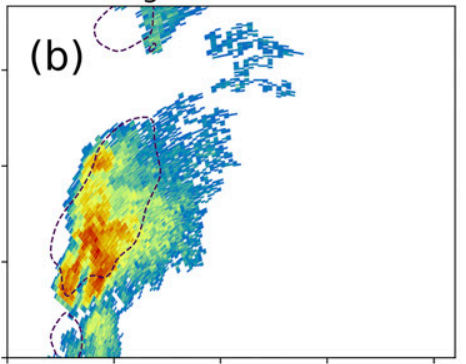

Time $=20: 45: 12$

Beam height at BWER $=7.6 \mathrm{~km}$

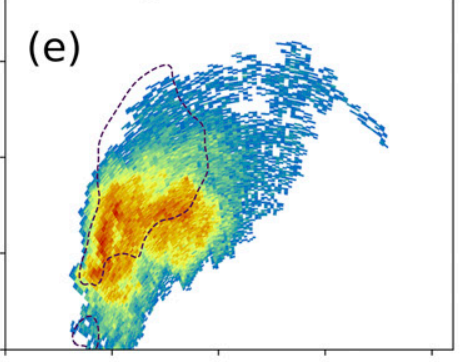

Time $=21: 19: 20$

Beam height at BWER $=5.8 \mathrm{~km}$

(h)

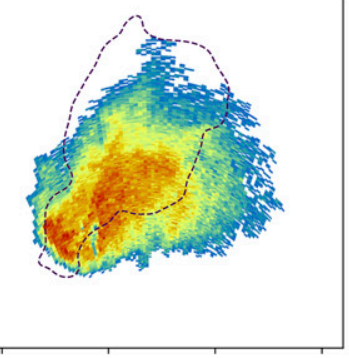

Time $=21: 57: 47$

Beam height at BWER $=4.8 \mathrm{~km}$

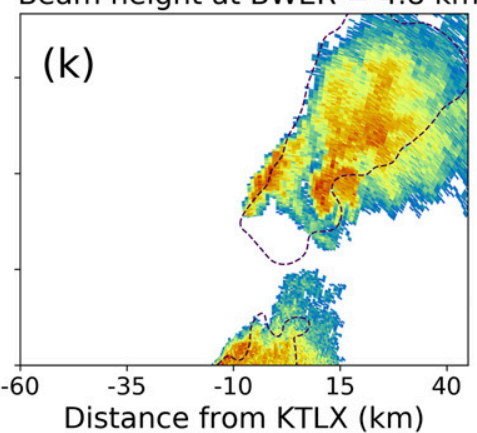

Time $=20: 36: 40$

Beam height at BWER $=7.6 \mathrm{~km}$

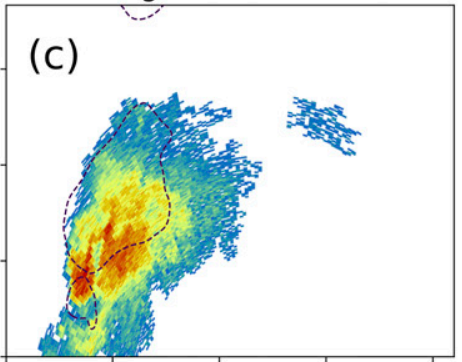

Time $=20: 49: 28$

Beam height at BWER $=8.8 \mathrm{~km}$

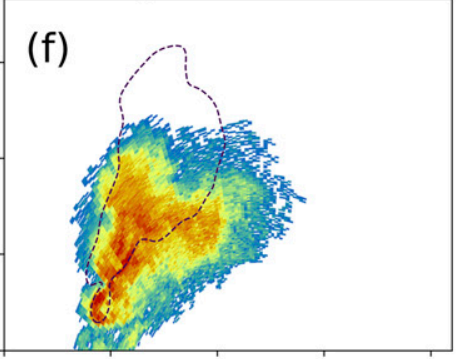

Time $=21: 23: 39$

Beam height at BWER $=5.8 \mathrm{~km}$

(i)

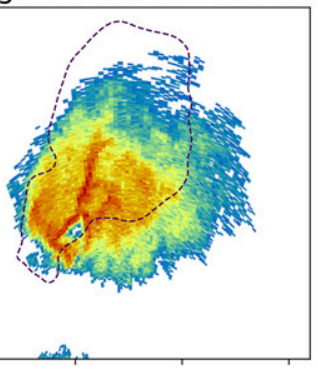

Time $=22: 10: 33$

Beam height at BWER $=5.9 \mathrm{~km}$

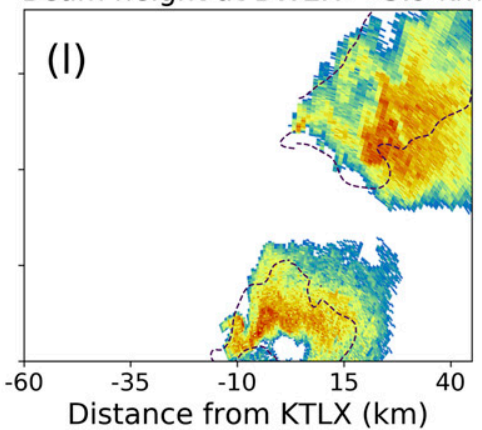

FIG. 7. KTLX 30-dBZ smoothed reflectivity contour (thin black line) at $0.5^{\circ}$ (elevation angle) and at midlevels (color fill) for the same times as shown in Figs. 4-6. Midlevel plots were generated by choosing an elevation angle that had a WER/BWER visible. Beam height in the title for each panel corresponds to midlevel elevation angle at the range of BWER/WER. 


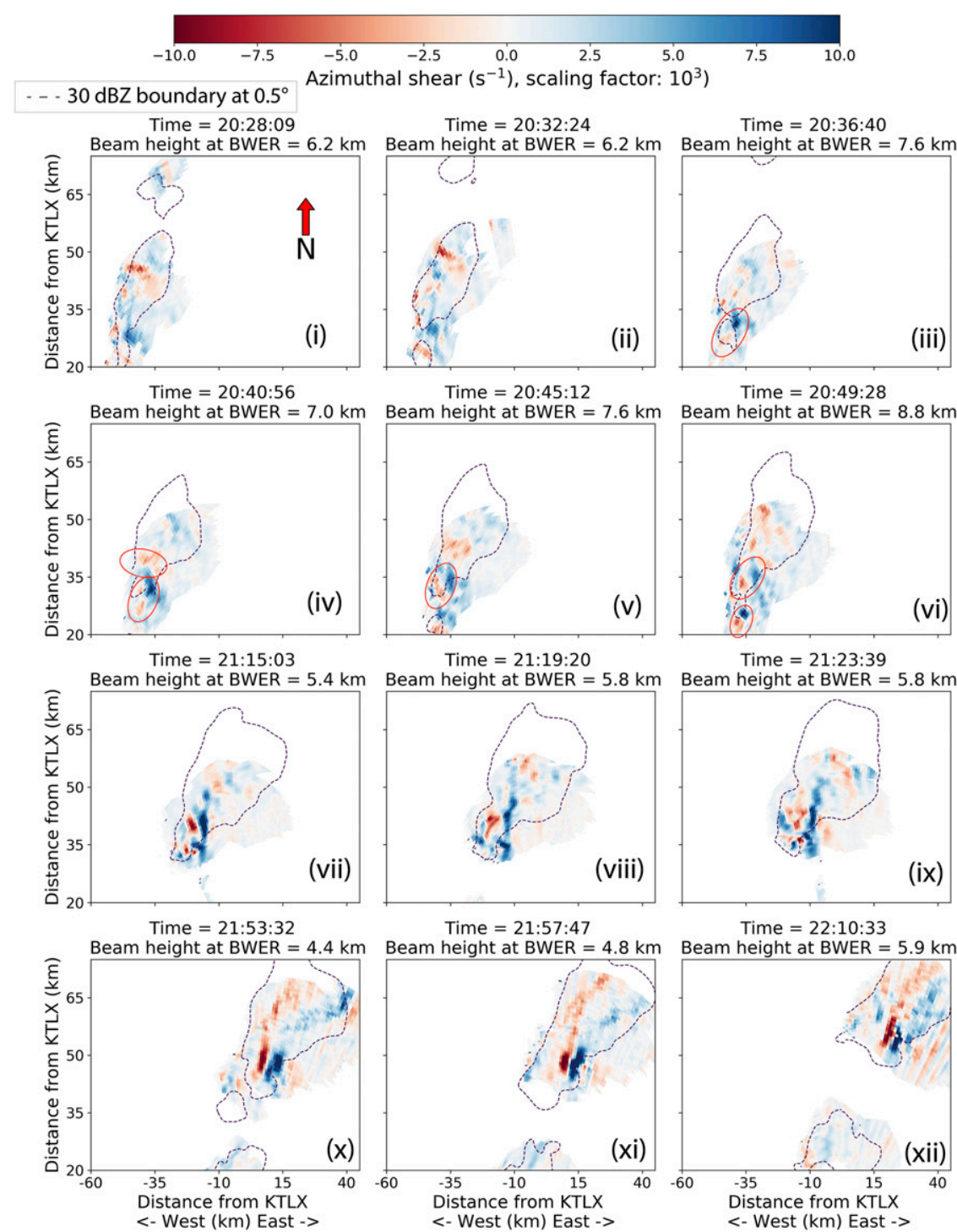

(a)

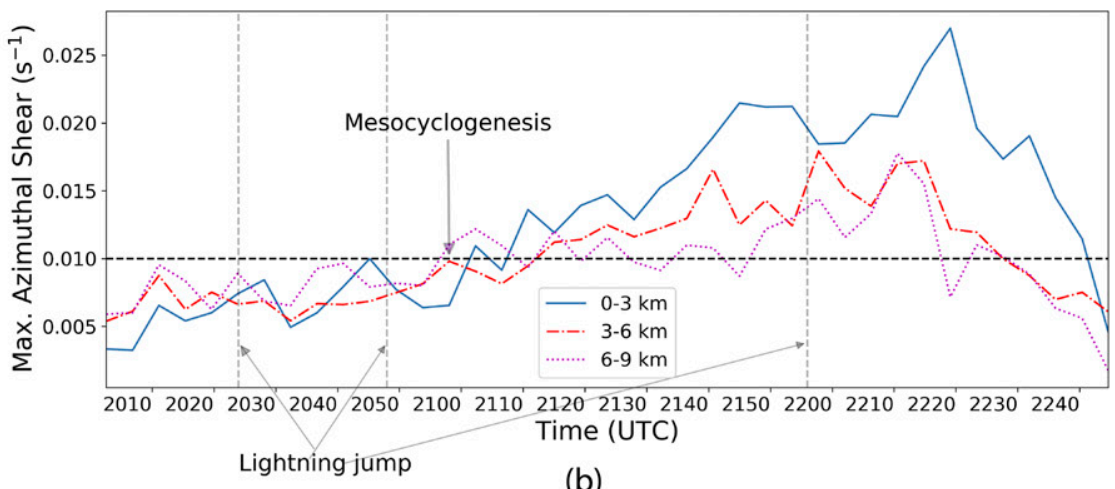

FIG. 8. (a) Azimuthal shear at the same times as gridded flash and reflectivity data in Figs. 4-7. Initial mesocyclone development signature is visible at 2036 UTC. Azimuthal shear values strengthen with time with at least two different mesocyclones present from 2040 to 2123 UTC. A single mesocyclone with large azimuthal shear values is visible from 2153 onward. Location of mesocyclone in (iv)-(ix) is within the same region as the maximum source density in Fig. 5. Thin black line marks the $30-\mathrm{dB} Z$ smoothed reflectivity contour at $0.5^{\circ}$ elevation angle. (b) Time series of maximum azimuthal shear (MAS) in the 0-3-, 3-6-, and 6-9-km cloud layers. Mesocyclogenesis is defined as the time when MAS in any one layer exceeds a threshold of $0.01 \mathrm{~s}^{-1}$. 


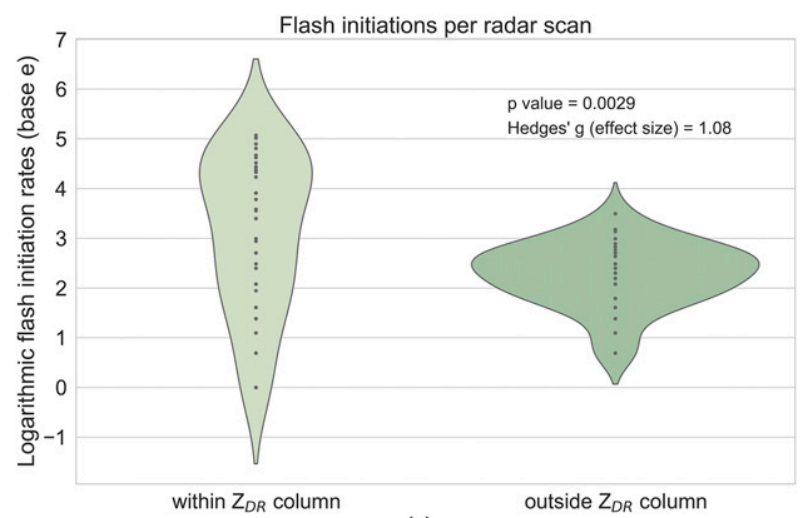

(a)

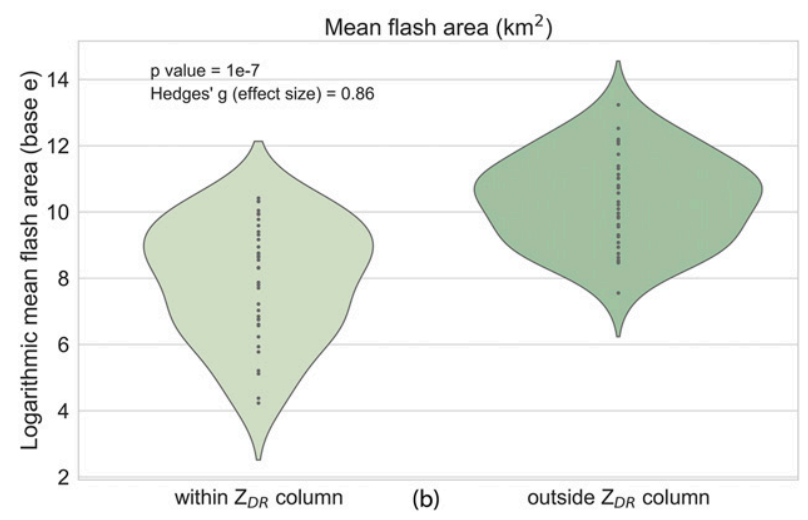

FIG. 9. Violin plots of (a) flash initiation rates and (b) mean flash area within and outside $Z_{\mathrm{DR}}$ column regions. A logarithmic scale is used on $y$ axes in both plots.

\section{b. Time-height variation in flash properties and lightning jump signature}

Both LMA source density (number of VHF sources in each grid cell) and flash initiation density (number of flash initiations in each grid cell) follow similar trends in lightning activity (Fig. 10). The time period between 2030 and 2040 UTC corresponds to highest total lightning flash rates ( $\sim 200$ per minute; cf. Fig. 3b). Just prior, from 2020 to 2030 UTC, maximum flash initiation occurred at an altitude of $11 \mathrm{~km}$, to the southeast of the main updraft core. Altitude of both the flash products gradually decreased in the next $10 \mathrm{~min}$. This is around the same time when the maximum flash initiation density clustered within the same region as the $Z_{\mathrm{DR}}$ column (cf. Fig. 4). The surge in source density at an altitude of $\sim 8 \mathrm{~km}$ could possibly be due to the small and frequent lightning flashes within the updraft region.

The $2 \sigma$ lightning jump algorithm of Schultz et al. (2009) was applied separately to the total lightning data from LMA and NLDN for the Edmond-Carney storm (Fig. 11). Between the two systems, three distinct lightning jumps were detected around 2024, 2048, and 2156 UTC, with the first one at least $24 \mathrm{~min}$ before the first severe hail report. Schultz et al. (2017) claimed that the highest flash density had a marked shift from the southern edge of the storm toward the updraft periphery within 10 min of a lightning jump. We notice a similar trend for the Edmond-Carney storm as shown in Figs. 4 and 5. The flash activity began to shift from the right edge of the forward flank in the south toward the location of identified $Z_{\text {DR }}$ column objects starting around 2036 UTC, approximately $12 \mathrm{~min}$ after the first lightning jump. Increases in maximum azimuthal shear were also observed within 1012 min of the second lightning jump at 2048 UTC (Fig. 8b) suggesting strong rotation and intensification of updraft. This observation supports the results reported in Stough et al. (2017) wherein the authors analyzed 19 supercells with varying intensity and found at least $70 \%$ of lightning jumps within $10 \mathrm{~min}$ of increases in mesocyclonic rotation.

\section{c. Charge analysis and flash initiation heights}

While some past studies associate anomalous or invertedpolarity storms with high $+\mathrm{CG}$ flash rates, such storms are often reported to produce relatively very few CG flashes, thereby rendering $\mathrm{CG}$ flash rates and polarity slightly less useful for analysis of the storm-scale charge structure (Fuchs et al. 2018). Therefore, it is pertinent to perform manual charge classification on the LMA data to examine the charge structure of the Edmond-Carney storm. Figures 12 and 13 show the storm charge structure obtained from manual charge classification performed for $>20 \mathrm{~min}$ worth of total LMA data. The storm maintained an inverted dipole with a shallow $(\sim 3 \mathrm{~km}$ deep) negative charge layer (blue), centered around an altitude of $11 \mathrm{~km}$ above MSL, sharing an interface with a deeper ( $\sim 7 \mathrm{~km}$ deep) positive charge layer (red) below, centered at an altitude of $7 \mathrm{~km}$ above MSL. Significantly, the upper charge layers were arranged in a manner inverse to the conventional tripolar storm charge model (with a negative charge layer in the middle). For reference, an operational radiosounding from Norman, Oklahoma at 1800 UTC indicated the $-40^{\circ} \mathrm{C}$ level at $\sim 9 \mathrm{~km}$ AGL (Fig. 1f). The high altitude of the negative charge layer suggests the presence of negatively charged ice crystals. The positive charge layer, however, resided within regions with mixed-phase and warm-rain processes. Hydrometeor classification analysis at 2115 UTC (not shown) also indicated the presence of dry snow and rimed ice particles at respective altitudes.

As discussed in section $4 \mathrm{~b}$ above, altitude of flash initiation and source density varied considerably throughout the lifetime of the Edmond-Carney storm. In Fig. 14, which is a snapshot of the storm's three-dimensional lightning activity between 2119 and 2123 UTC, it can be seen that relatively sparse VHF sources were arranged along an outer ring surrounding a densely packed inner core (Fig. 14d). Elevation views along east-west and north-south directions (Figs. 14b and 14e, respectively) reveal that the half-ring of outermost, larger flashes on the upshear- and downshear-right (in the plan view; Fig. 14d) were dominated by VHF sources distributed within a relatively thin layer centered at $10 \mathrm{~km}$ above MSL. VHF sources associated with overshooting tops (Calhoun et al. 2013; MacGorman et al. 2017) were evident at and above 15-km altitude (Figs. 12, 13, and $14 \mathrm{a}, \mathrm{b}, \mathrm{e})$. VHF sources below and just upshear of the overshooting top appear as the densely packed inner core in the plan view 


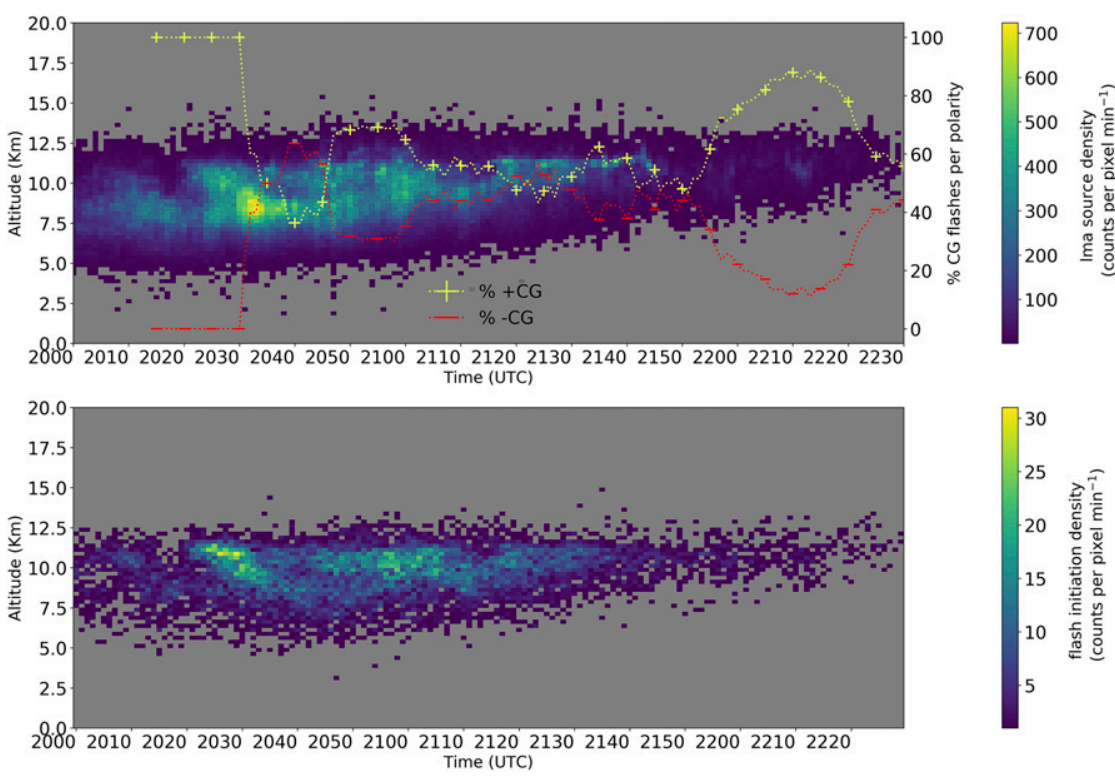

FIG. 10. Time-height variation of (a) flash source density and (b) flash initiation density in the Edmond-Carney storm as derived from gridded LMA data. Percentage of positive and negative CG flashes out of total CG flashes is plotted along the $x$ axis (yellow and red lines, respectively). LMA data correspond to aggregated values per minute. CG data corresponds to a 15-min rolling mean.

(Fig. 14d) and are largely distributed between 7 and $11 \mathrm{~km} \mathrm{MSL}$ (Fig. 14b). Moving away from the inner core, sources gradually descend to an altitude of $\sim 6 \mathrm{~km}$ on either side, likely corresponding to precipitation in the rear and forward flanks (Fig. 14b).
These moderately dense sources are part of the interior ellipse of sources surrounded by an outermost ring (Fig. 14d). At least one more cluster of sources can be seen between 5 and $9 \mathrm{~km}$ MSL in the far forward flank and anvil region (Fig. 14b).

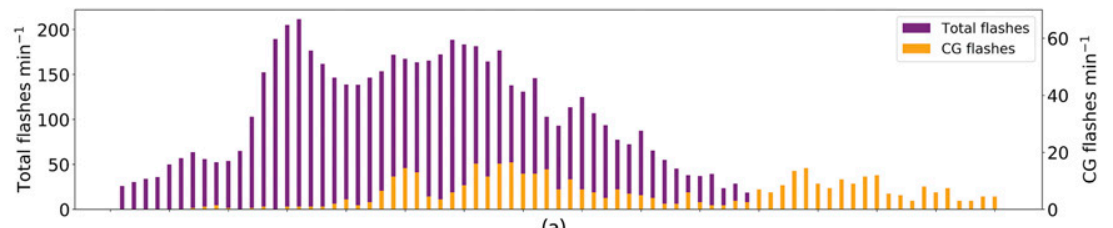

(a)

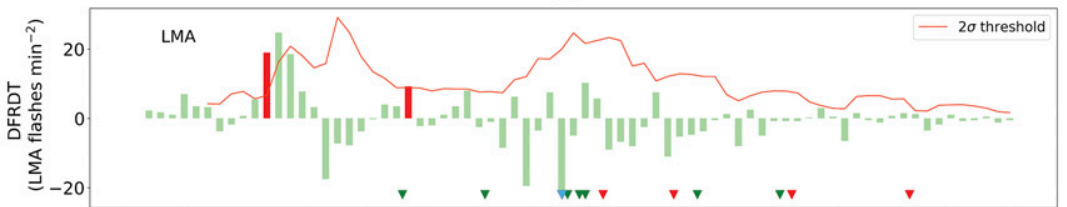

(b)

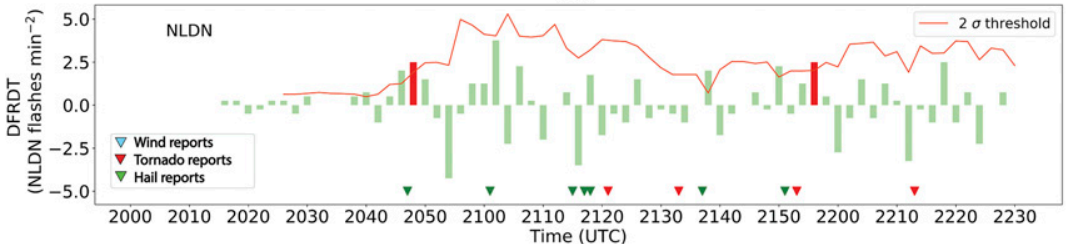

(c)

FIG. 11. (a) Time series of total and CG flash rates in the Edmond-Carney storm. (b) Time rate of change of the total flash rates (DFRDT) from OKLMA calculated using a threshold of $2 \sigma$ standard deviation in conjunction with a minimum flash rate of $10 \mathrm{~min}^{-1}$. Red bars represent times where a lightning jump is detected by the lightning jump algorithm. The orange line represents the $2 \sigma$ threshold at each time step, and severe weather reports are plotted along the $x$ axis. (c) As in (b), but using NLDN total flash rates. 

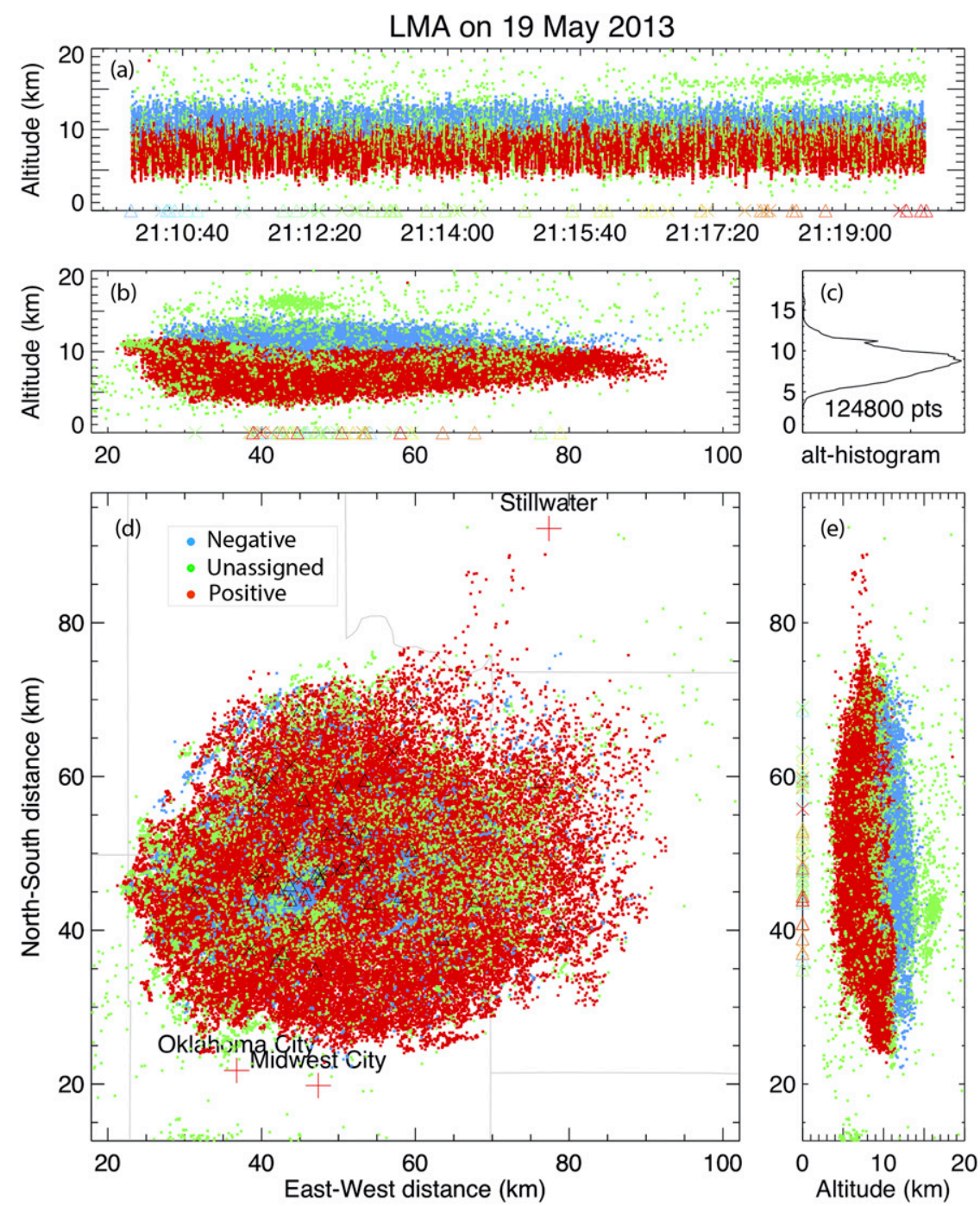

FIG. 12. Manual charge classification for the Edmond-Carney storm from 2110 to 2120 UTC. (a) Time vs height plot of all lightning sources, (b) east-west distance vs height plot of all lightning sources, (c) histogram for all lightning sources, (d) top-down view of all lightning sources with city names and county boundaries plotted, and (e) north-south distance vs height plot of all lightning sources. Positive, negative, and unclassified charge regions are colored red, blue, and green, respectively. Triangles and cross symbols indicate negative and positive CG flashes, respectively.

To further investigate the association between local charge structure and polarimetric storm features, we overlaid VHF sources associated with negative and positive charge regions on top of cross-section plots of radar reflectivity $Z$ and differential reflectivity $Z_{\mathrm{DR}}$ (Fig. 15). Figures $15 \mathrm{a}-\mathrm{c}$ represent the backsheared anvil region where VHF sources were clustered within the 10-11-km layer. Figures 15d-f correspond to the weak echo region (WER) or $Z_{\mathrm{DR}}$ column region, wherein VHF sources from at least two different flashes are discernible. It can be seen that positive polarity VHF sources followed a negative slope on the left of the $Z_{\mathrm{DR}}$ column, or directly atop the WER. These sources descended from $\sim 10$ to $6 \mathrm{~km}$ above MSL before rising again to an altitude of $10 \mathrm{~km}$ just above the $Z_{\mathrm{DR}}$ column.
Negative polarity sources were, however, densely clustered in a small region located at $\sim 11 \mathrm{~km}$ above MSL. Similarly, on the other side of the $Z_{\mathrm{DR}}$ column, sources descend to an altitude of $6 \mathrm{~km}$ out to $45-\mathrm{km}$ range followed by a rise aligned along a positive slope. Finally, in the forward flank region, a layered structure was evident, wherein both negative and positive polarity sources descended along with maximum reflectivity, probably forming the forward flank boundary. This descending pattern was a manifestation of graupel falling away from the core updraft region into the forward flank (Fig. B1). These findings conform to the conceptual model of supercell charge structure originally proposed by Bruning et al. (2010). 

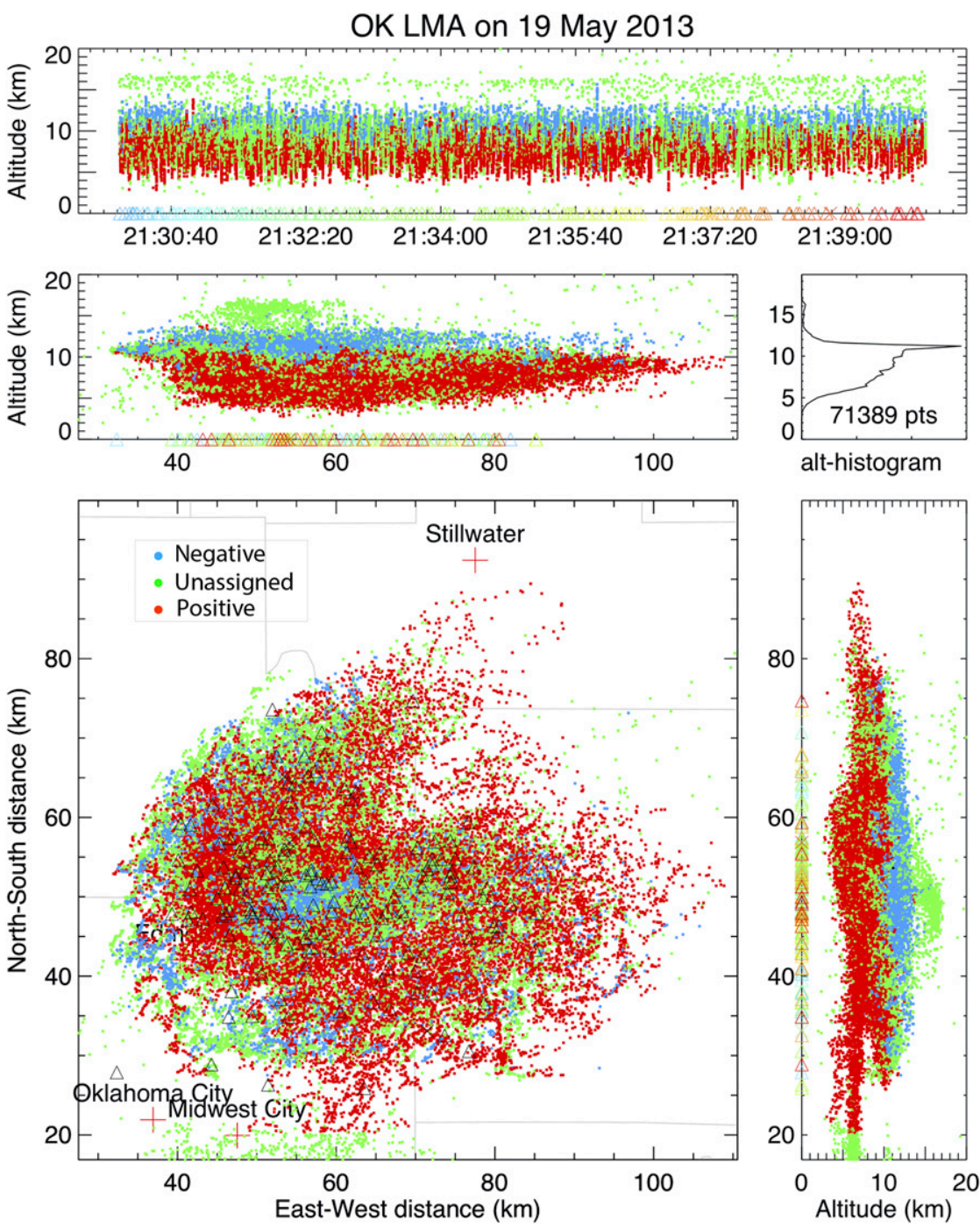

FIG. 13. As in Fig. 12, but for 2130-2140 UTC, a period that includes a tornado reported at 2133 UTC

MacGorman et al. (2011) discussed the complex nature of storm charge structure. For example, a lower negative charge layer may exist below the main positive charge region due to the contribution from inductive processes (driven by the electric field of the inverted dipole). Some studies (e.g., Weiss et al. 2008) also suggest that negative charging of graupel in the nearby regions of weaker updrafts can also further complicate the process. Therefore, it is reasonable to expect the total lightning activity to be dominated by inverted-polarity intracloud (or - IC) flashes and predominantly + CG flash strikes. However, the reason for relative absence of any lower negative charge layer in the Edmond-Carney storm is not clear (cf. Figs. 12 and 13). Tessendorf et al. (2007) documented a similar observation for the 22 June 2000 multicellular storm wherein no lower charge layer was found when +CG flashes occurred. CG flash rates of either polarity had comparable values ( $\sim 6$ flashes per minute) in the storm from 2100 to 2120 UTC, which cannot be explained by any of the mechanisms above.

\section{d. Spatiotemporal trends in polarimetric and lightning signatures}

Based on results from previous studies highlighting the role of updraft volume rather than peak updraft speeds in determining flash rates (Lang and Rutledge 2002; Schultz et al. 2017), we investigated whether $Z_{\mathrm{DR}}$ and $K_{\mathrm{DP}}$ column volume was superior at explaining flash initiation activity in the Edmond-Carney storm. Figures $16 a-d$ depict total flash rates along with temporal variation in volume and height of $Z_{\mathrm{DR}}$ and $K_{\text {DP }}$ columns, respectively. At least two useful inferences can be made from these plots. First, $Z_{\mathrm{DR}}$ column heights correlated better with the overall flash rates than $K_{\mathrm{DP}}$ column heights. Second, the temporal variation in $Z_{\mathrm{DR}}$ column volume closely matched the variability in flash rates in real time, with 

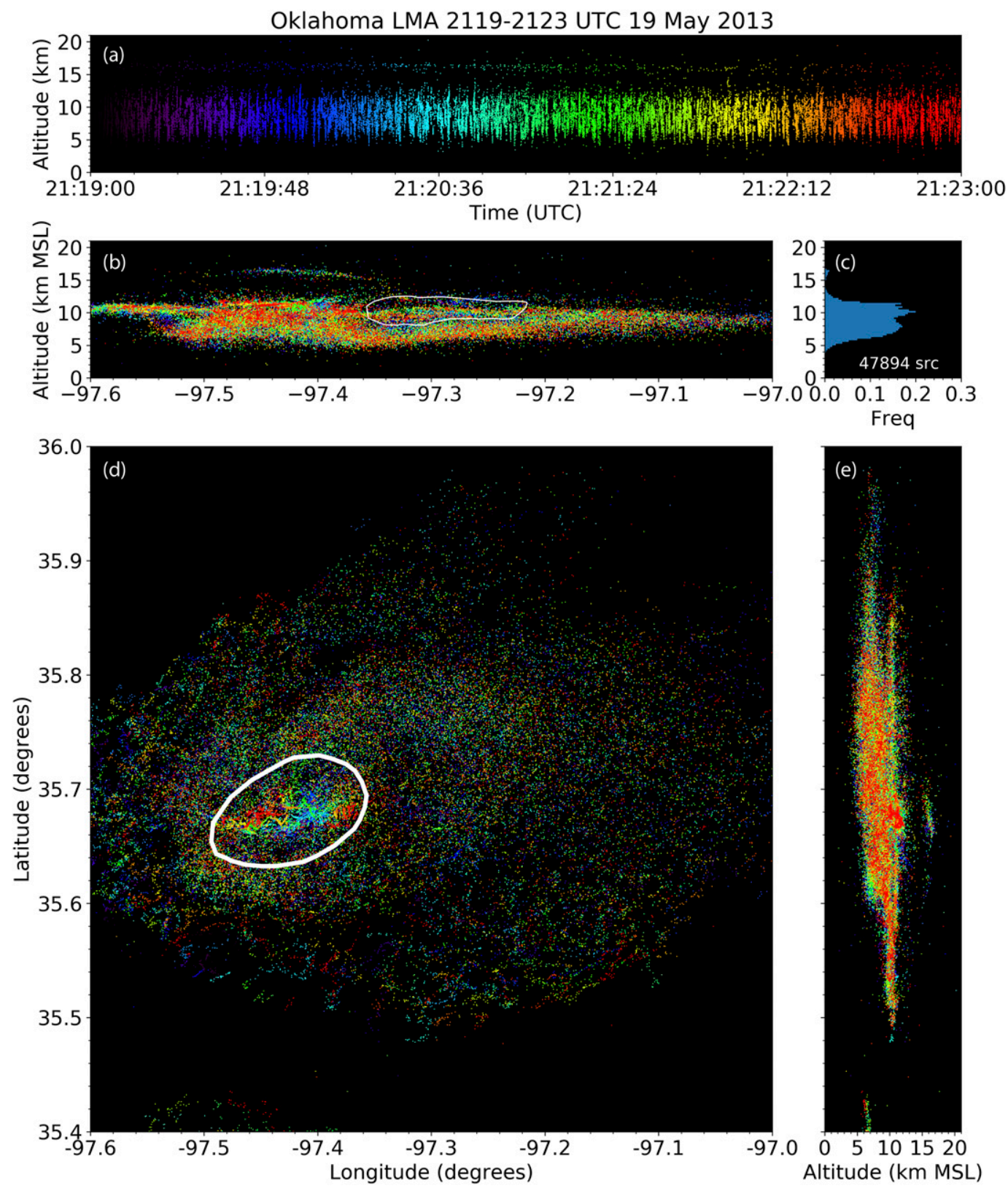

FIG. 14. (a)-(e) Panel plot of filtered VHF sources during the KLTX radar volume scan starting at 2119 UTC. Only the VHF sources that met the following conditions were included: (i) detected by seven or more stations and (ii) reduced $\chi^{2}$ less than or equal to 1 . All panels are in the same order as in Fig. 12. White boundaries in (b) and (d) are meant to orient the reader and support the text description of different clusters of VHF sources. The boundary in (b) highlights sources in the far forward flank and anvil region while the boundary in (d) depicts the distribution of sources in an elliptical fashion surrounded by an outer ring of VHF sources.

Spearman correlation coefficient of 0.72 at zero lag as opposed to a value of 0.11 for $K_{\mathrm{DP}}$ columns. It is worth noting that the heights and volumes of $Z_{\mathrm{DR}}$ and $K_{\mathrm{DP}}$ columns became less correlated with OKLMA total flash rate after 2132 UTC. We interpret this abrupt change in behavior as a manifestation of reduced updraft strength at higher altitudes. Even though the total column volume was high, it is the volume within $1 \mathrm{~km}$ of environmental melting level (below $-10^{\circ} \mathrm{C}$ level) that contributed the most to the total volume at and after 2132 UTC (Fig. 17c). Thus, it is likely that the updraft intensity was too weak to penetrate the mixed-phase region above $-10^{\circ} \mathrm{C}$ levels where graupel and ice crystals could undergo collisions for enough charge separation and flash initiation. However, the lightning jump at 2156 UTC was detected from NLDN total 

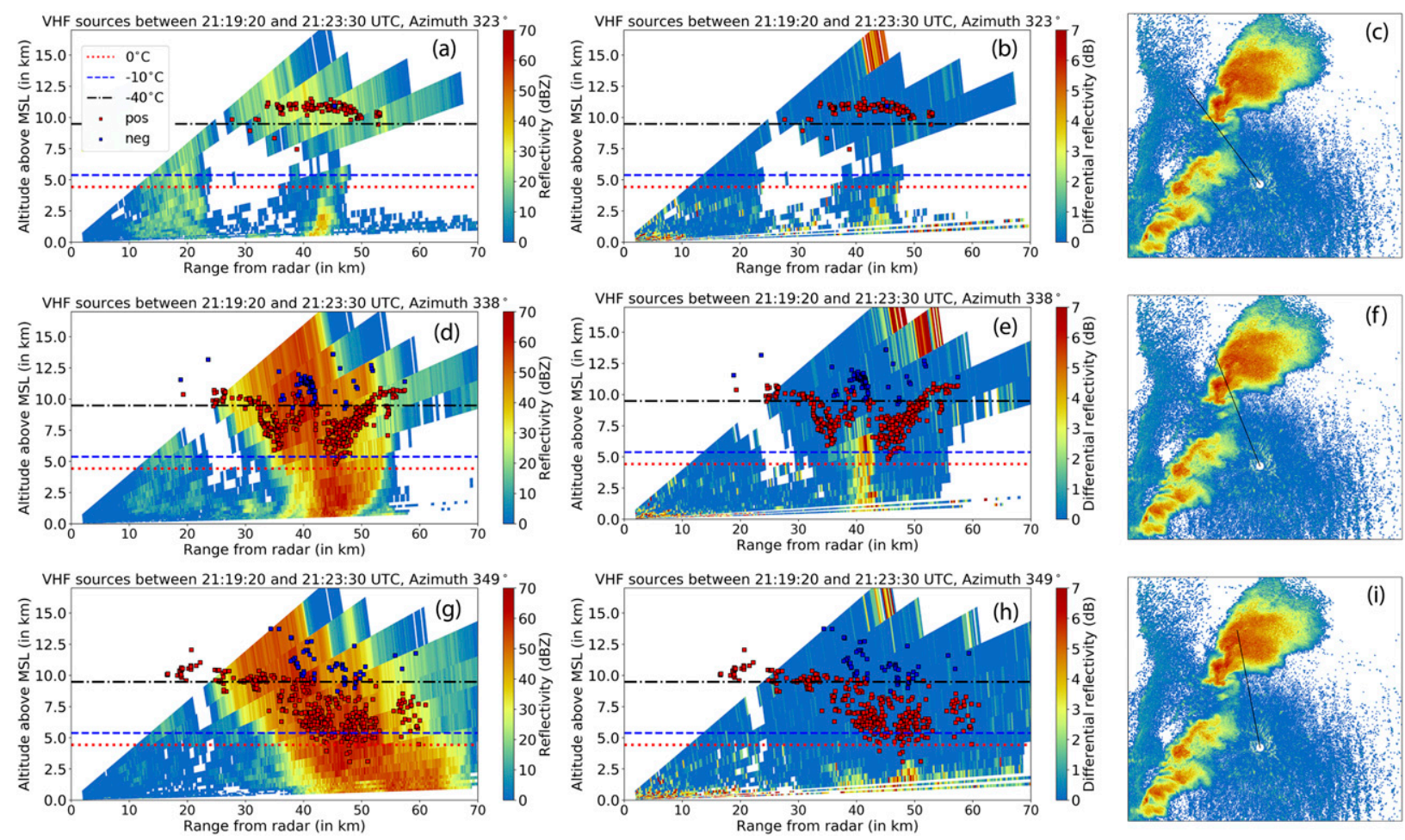

FIG. 15. Positive (red) and negative (blue) VHF sources overlaid on pseudo-RHI plots of (a),(d), (g) $Z$ and (b), (e),(h) $Z_{\mathrm{DR}}$ for the 2119 UTC KTLX volume scan. (c),(f),(i) Azimuths for plotted cross sections shown as black line over KTLX reflectivity data at $0.5^{\circ}$ elevation. Azimuths of (top) $323^{\circ}$, (middle) $338^{\circ}$, and (bottom) $349^{\circ}$ clockwise from north, corresponding to the backsheared anvil, weak echo region, and forward flank regions of the storm, respectively. Only the VHF sources within $500 \mathrm{~m}$ of the azimuth are overlaid to illustrate the charge structure. Notice the $Z_{\mathrm{DR}}$ column in (e) at $\sim 40-\mathrm{km}$ range, right where the weak echo region is visible in $(\mathrm{d})$.

flash rates. This result also highlights the potential challenges and pitfalls of relying solely on the $Z_{\mathrm{DR}}$ column volume and single lightning sensor system as a diagnostic parameter for storm severity in an operational setting. We therefore propose using additional controls, such as the extension of $Z_{\mathrm{DR}}$ columns above the environmental melting level, and data from other ground-based lightning detection systems to make better decisions in such scenarios. Independent confirmation of updraft depth can also, apparently, be provided by total lightning data: as shown here its information content can diverge from that in the $Z_{\mathrm{DR}}$ volume trend.

Lightning jumps (at 2024, 2048, and 2156 UTC; section 4b) can be understood in terms of increased updraft speeds and larger updraft volume. Physically, a larger interface between updrafts and downdrafts led to frequent flashes of relatively small size in and around updraft core (Schultz et al. 2017). There was indeed an increase in $Z_{\mathrm{DR}}$ column volume above the melting level around the same times as these lightning jumps (Figs. 16e,f). Specifically, the volume of $Z_{\mathrm{DR}}$ columns was the largest at higher altitudes at these three times. Thus, our observations support the hypothesis proposed by Schultz et al. (2017). This result further confirms that transient microphysical and draft variability as indicated by $Z_{\mathrm{DR}}$ columns and lightning can work together as indicators of severe weather risk in a warning decision environment. Future studies are also warranted in using rapid scan polarimetric measurements for capturing the transient microphysical and dynamical characteristics of severe storms to further refine these relationships.

Since $Z_{\mathrm{DR}}$ and $K_{\mathrm{DP}}$ columns are used as proxies for storm updraft, it makes more sense to compare flash initiations that occurred within the updraft region (i.e., within the bounding box of objectively identified columns) to quantify the direct effect of charging of hydrometeors within the updraft core. The $Z_{\mathrm{DR}}$ column volume again proves to be a better predictor for lightning initiation rates than $K_{\mathrm{DP}}$ column volume (Figs. 17a,b). Flash initiation rates as high as 35 per radar volume scan were found to occur at the same time when $Z_{\mathrm{DR}}$ column volume attained a peak value of approximately $330 \mathrm{~km}^{3}$. The $K_{\mathrm{DP}}$ column volume, on the other hand, did not follow the same trend, as maximum initiation rates occur either before or after peak $K_{\mathrm{DP}}$ volumes. Moreover, low flash initiation rates ( $\sim 10-20$ per radar scan) occurred when $K_{\text {DP }}$ column volume attained peak values around $300 \mathrm{~km}^{3}$. Spearman correlation coefficient between $Z_{\mathrm{DR}}$ column volume and total flash initiation rates was found to be 0.51 as opposed to a value of 0.32 for $K_{\mathrm{DP}}$ columns (excluding data points after 2132 UTC). We conclude that properties of $Z_{\mathrm{DR}}$ columns capture flash rate variability better than $K_{\mathrm{DP}}$ columns. Furthermore, $Z_{\mathrm{DR}}$ columns 

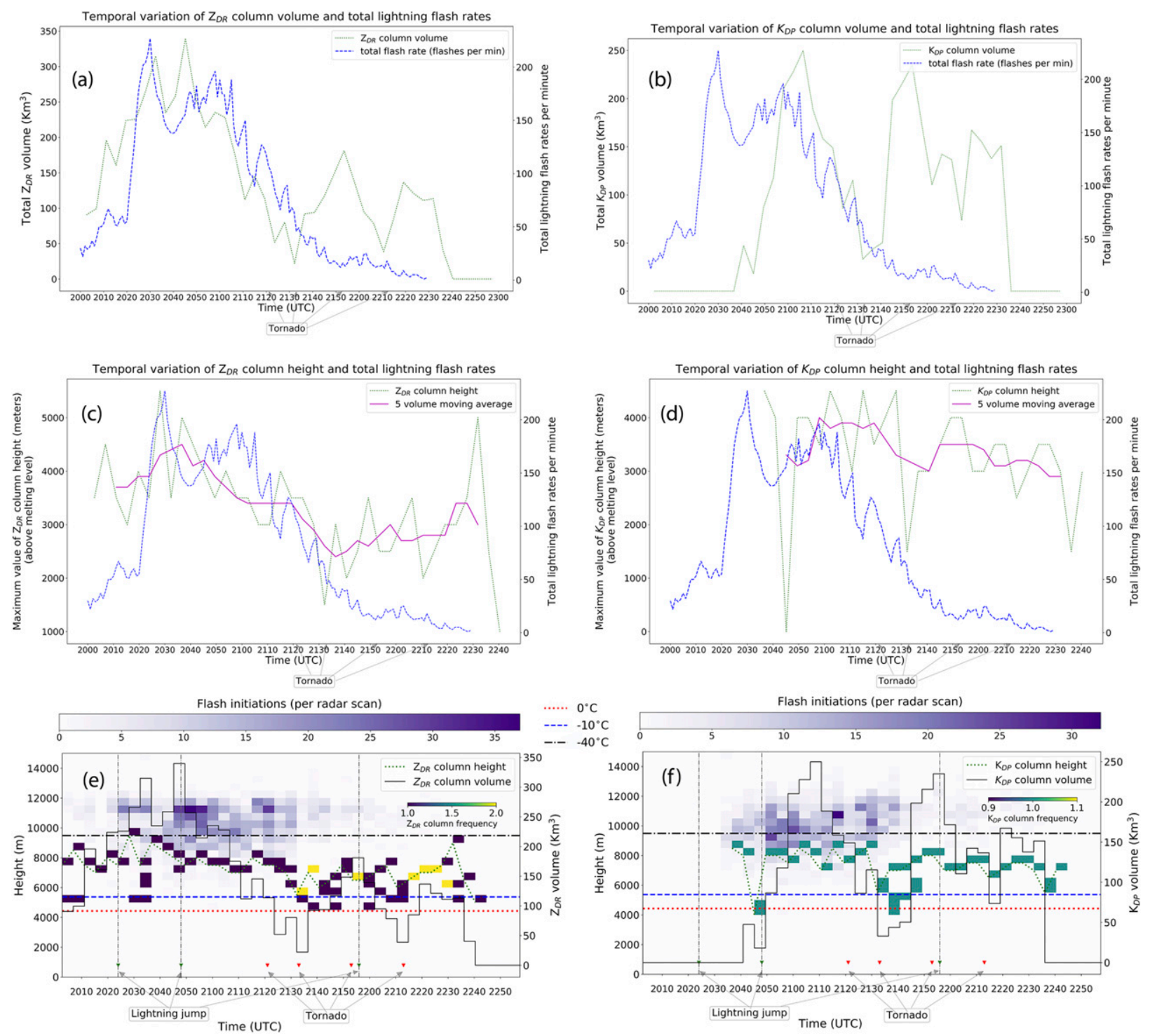

FIG. 16. Time series of total lightning flash rates and volumes of (a) $Z_{\mathrm{DR}}$ column objects and (b) $K_{\mathrm{DP}}$ column objects. When multiple objects were detected in a single radar volume, height of the tallest column and aggregated volume of all the column objects is shown. Times of tornado reports are indicated along the $x$ axes. Time series of total lightning flash rates and heights of (c) $Z_{\mathrm{DR}}$ column objects and (d) $K_{\mathrm{DP}}$ column objects. Magenta line represents the moving average of the column heights over five radar volume scans. Time series plots of (e) $Z_{\mathrm{DR}}$ column and (f) $K_{\mathrm{DP}}$ column characteristics. Volumes of identified column objects are plotted as a histogram (black line). Flash initiations at different altitudes were calculated by aggregating values within the bounding boxes of all column objects at that time step (purple shades). Frequency of the column objects at each altitude is overlaid using color fill. Tornadogenesis and lightning jump reports are indicated along the $x$ axes.

hold promise for relating storm microphysics and dynamics with the evolution of storm electrical structure.

\section{e. Limitations}

As with any other observational study, there are associated limitations and as-yet unanswered questions:

- Historically, inverted polarity storms have been reported to produce predominantly + CG flashes or negligible CG flash rates (MacGorman et al. 2011, and references therein). The charge analysis plots discussed above (Figs. 12 and 13) correspond to times when overall CG flash rates were less than four flashes per minute, but still had contribution from CG flashes of either polarity. However, even at other times when CG flash rates were substantially high (e.g., from 2100 to 2110 UTC, when CG flash rates reached a value of six flashes per minute), flashes of either polarity were present. Most of the flashes during this time still hinted toward an inverted 

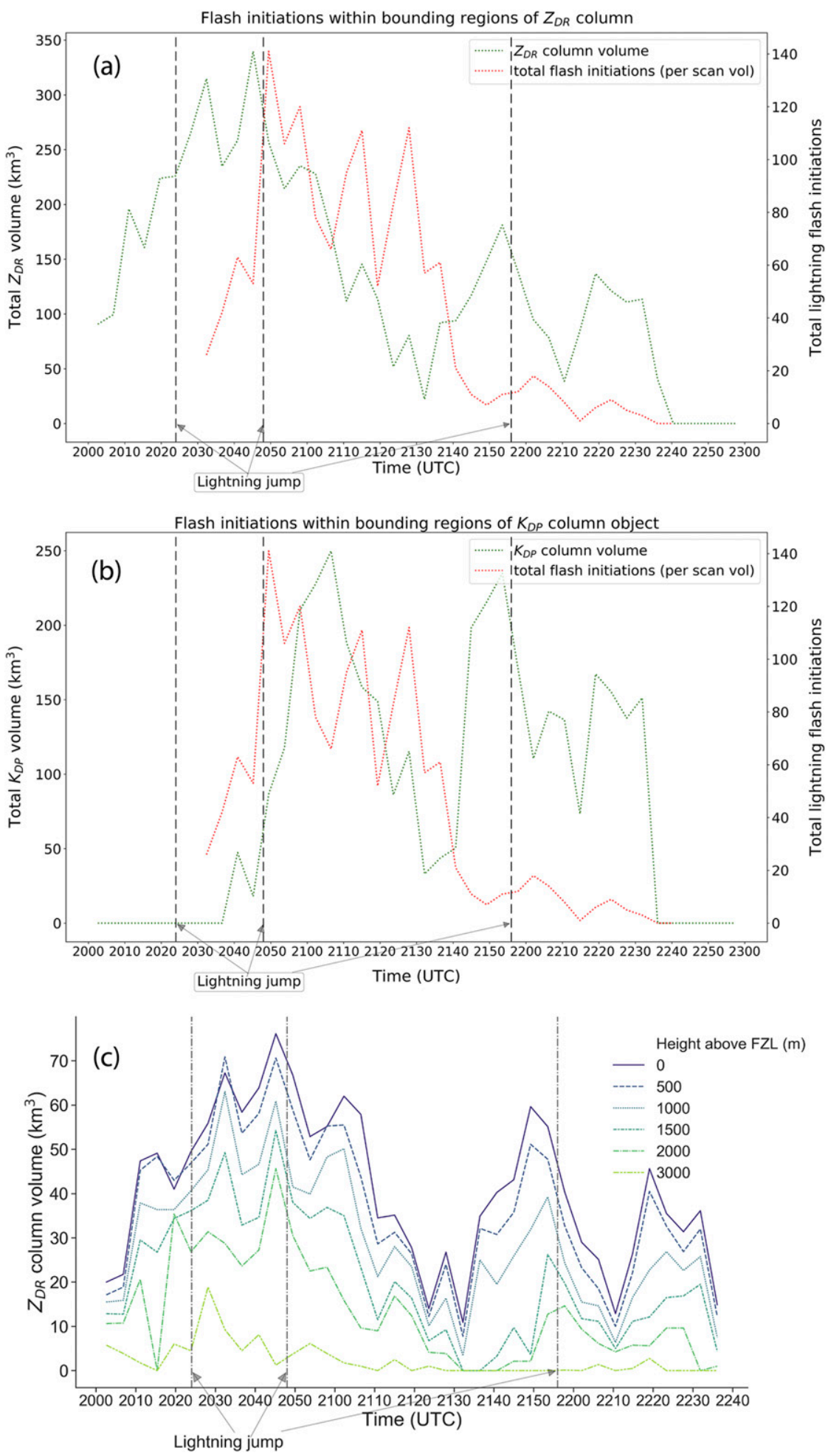

FIG. 17. Time series of total flash initiations within the bounding box region of identified (a) $Z_{\mathrm{DR}}$ column objects and (b) $K_{\mathrm{DP}}$ column objects. Initiations within all the bounding boxes were aggregated when multiple objects were detected in a single radar volume scan. (c) Time series of $Z_{\mathrm{DR}}$ column volume at $0,0.5,1,1.5,2$, and $3 \mathrm{~km}$ above the environmental melting level. 
dipole structure (not shown). We speculate that the local kinematics were enhancing charging of lower layer in the regions producing $+\mathrm{CG}$ flashes.

- Reduced OKLMA total lightning flash rates between 2130 and 2230 UTC merit further investigation. During this time, $Z_{\mathrm{DR}}$ columns of substantial volume were present, but the lightning flash rates plummeted (Figs. 16a,b). At least the first peak in $Z_{\mathrm{DR}}$ and $K_{\mathrm{DP}}$ column volume within this time period coincides with a lightning jump detected from NLDN total flash rates but was missing in OKLMA flash rates (Figs. 17b,c). As explained in section 4d above, this drastic reduction in lightning flash rates probably reflects weakening of updrafts and their inability to loft supercooled drops in the upper mixed-phase region $\left(-20^{\circ} \mathrm{C}\right.$ and above) to ensure enough charge separation during collisions between ice crystals and graupel. Thus, lightning arguably makes it easier to diagnose the shift in the microphysical character of the storm than any of the polarimetric variables. The $K_{\mathrm{DP}}$ column volume was noticeably high during the same period. We speculate either wet growth of hail and shedding of small drops from hailstones to be a possible cause for this behavior. However, we cannot ignore possible issues with the $K_{\mathrm{DP}}$ retrieval algorithm in the mixed-phase region due to nonuniform beam filling.

- Some caveats related to manual charge classification include (i) no statistical information regarding charge magnitudes, (ii) noise in the LMA data, even at reduced $\chi^{2}=1$ for seven stations, can lead to reduced accuracy in charge region identification, especially when there are many small flashes near strong updrafts in the storm, (iii) total lightning detection efficiency is highly dependent on the number of stations and their distances from the storm. Since the central OKLMA had only 10 active stations out of which at least three had $<20 \%$ contribution to the overall detected VHF sources, the signal-to-noise ratio could have been low, and (iv) LMA data are useful for determination of charge structure in only those storm regions with ongoing lightning activity.

\section{Conclusions}

In this study, we investigated the physical linkages between mixed-phase updrafts and lightning flash characteristics for a tornadic supercell through radar derived polarimetric signatures like $Z_{\mathrm{DR}}$ and $K_{\mathrm{DP}}$ columns. Quantitative analysis of lightning flash rates and other gridded products such as mean flash area and flash initiation density confirm findings reported in previous studies which used dual-Doppler analyses to infer updraft velocities. Flashes occurring within $Z_{D R}$ column region were found to be 5 times more frequent and $\sim \mathcal{O}(10)$ smaller than the flashes occurring outside. Both these results were statistically significant at $95 \%$ confidence level (see Fig. 9). Additionally, we demonstrate the utility of $Z_{\mathrm{DR}}$ columns as a proxy for updrafts in the absence of other sources of information about the vertical wind structure of a storm.

The Edmond-Carney storm maintained an inverted polarity charge structure in its mature phase, during which it also produced at least two tornadoes (see Figs. 12 and 13). Negative (positive) charge layers were centered around an altitude of $11 \mathrm{~km}(7 \mathrm{~km})$ above MSL during this period. These heights correspond to temperatures near $-40^{\circ}$ and $-18^{\circ} \mathrm{C}$, respectively, suggesting negatively charged ice crystals in upper regions and positively charged mixed-phase precipitation in the midlevels. A lower negative charge layer which was expected based on observed rates of $+\mathrm{CG}$ flashes $(\sim 10$ per minute) was absent in our case. We do not have sufficient data to explain any physical mechanisms that might have contributed to its absence.

Of the four tornadoes reported in the Edmond-Carney storm, at least one (at 2153 UTC) occurred during a surge in $+\mathrm{CG}$ flash rates. Increases in $Z_{\mathrm{DR}}$ column volume were also observed at the same time (see Fig. 3c). The other three tornadoes were not associated with such +CG surges. Similar patterns have been reported in the past, thereby reconfirming that the trends in $\mathrm{CG}$ flash rates alone are not adequate as a parameter to predict tornadogenesis. The $Z_{D R}$ columns attained maximum heights of up to $4 \mathrm{~km}$ and above around the same time as the lightning jumps see Fig. 16a). Deeper $Z_{D R}$ columns around this time also resulted in larger volumes extending at least $3 \mathrm{~km}$ (up to $-20^{\circ} \mathrm{C}$ ) above the melting level (see Fig. 17c) thereby validating the utility of $Z_{D R}$ columns as a proxy for mixed-phase updrafts (see Figs. 16a-d).

Mesocyclone development and attendant updraft intensification gave rise to interesting spatial patterns with products like lightning flash source and initiation density clustered to the southeast of $Z_{\mathrm{DR}}$ columns over the right forward-flank region initially and shifting northward to align with the location of $Z_{\mathrm{DR}}$ columns as time progressed (see Figs. 4, 5, and 8). We also demonstrated the utility of trends in $Z_{\mathrm{DR}}$ column volume to capture the variation in lightning characteristics, especially the total lightning flash rates in a supercell storm. A major contribution of this study lies in highlighting the potential use of polarimetric signatures like $Z_{\mathrm{DR}}$ and $K_{\mathrm{DP}}$ columns coupled with lightning data to infer changes in the depth and width of the mixed-phase updraft. We showed that the highest flash rates were accompanied by deeper and wider updrafts early in the storm lifetime (cf. Fig. 16c and Fig. A1). Lower correlation between $Z_{D R}$ column volume and total flash rate between 2130 and 2230 UTC was likely because of limited penetration of $Z_{D R}$ columns above $-10^{\circ} \mathrm{C}$ (see Figs. 16a,c and 17c). Moreover, spatial alignment of $Z_{\mathrm{DR}}$ columns and highest flash initiation and source density served as a good tool to infer location of storm updraft with respect to the overall storm structure (see Figs. 4 and 5).

This study demonstrated the utility of polarimetric observations of supercells as an aid to storm-scale analysis of microphysical and lightning properties. At the time of this writing, the authors are embarking on additional similar analyses of both tornadic and nontornadic storms in the Southeast United States. These results are stepping stones toward more general explanations of the underlying physical linkages between storm kinematical and electrical evolution. These objectives are also supported by 


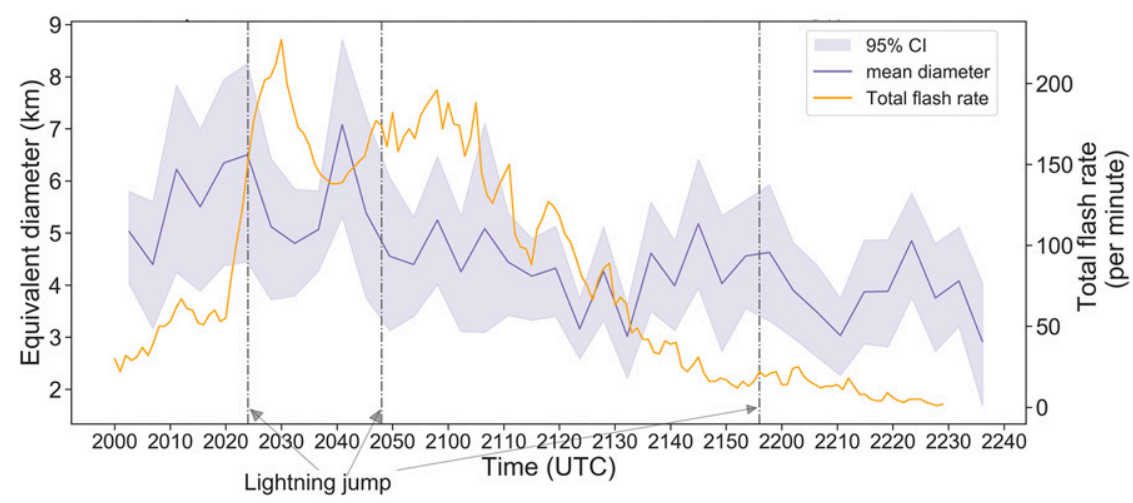

FIG. A1. Time series of equivalent diameter of a circle with the same area as $Z_{\mathrm{DR}}$ column. The time series data takes into account the variability in $Z_{\mathrm{DR}}$ column size at different altitudes. The purple line represents the mean value across all altitudes, and the shaded region represents the $95 \%$ confidence interval around the mean. The orange line represents total flash rate.

ongoing research efforts at National Severe Storms Laboratory (United States) and elsewhere to obtain rapid-scan polarimetric data for improved understanding of storm structure and dynamics.

Acknowledgments. We thank Ron Holle and Martin Murphy at Vaisala for providing additional NLDN data and answering our questions about the NLDN upgrade. Thanks are also given to Dr. Vanna Chmielewski for insightful discussions on source detection efficiency calculations for OKLMA. We would also like to thank the creators of and contributors to several open source Python software packages, especially NumPy (Harris et al. 2020), SciPy (Virtanen et al. 2020), xarray (Hoyer et al. 2019), and MetPy (May et al. 2020), which were used in this study. Most of the data visualization for this study was performed using matplotlib (Hunter 2007; Caswell et al. 2019). Segmentation results were visualized and further processed for accurate labeling using napari (Sofroniew et al. 2019). We would also like to express our sincere gratitude to the three anonymous reviewers whose comments significantly improved our analyses and interpretations. Computational support for this research was provided by the ITaP and College of Science IT research computing staff at Purdue University. This research was partially funded by NSF Grant AGS-1741003 and using federal funds under Award NA19OAR4590209 from NOAA, U.S. Department of Commerce. The statements, findings, conclusions, and recommendations are those of the authors and do not necessarily reflect the views of the NOAA or the U.S. Department of Commerce.

Data availability statement. Level II KTLX data files for the duration 2000-2300 UTC were obtained from the NCEI NEXRAD inventory [NOAA National Weather Service (NWS) Radar Operations Center 1991]. OKLMA data are maintained in an archive at the National Severe Storms Laboratory (Norman, Oklahoma) and are available upon request. NLDN data are an access controlled commercial dataset held by Vaisala. Oklahoma mesonet (Brock et al. 1995; McPherson et al. 2007) data can be obtained from https://doi.org/10.15763/dbs.mesonet.standard. Code and processed data files used to generate plots in this paper are available at https://doi.org/10.5281/zenodo.4716927.

\section{APPENDIX A}

\section{Object Segmentation Procedures}

\section{a. $Z_{D R}$ and $K_{D P}$ column identification}

As discussed in section $3 \mathrm{~b}$, the first step in image segmentation of $Z_{\mathrm{DR}}$ and $K_{\mathrm{DP}}$ column objects involves automatic contrast normalization (see Table A1 for parameters used to retrieve $K_{\mathrm{DP}}$ field). A Gaussian distribution is fit to the intensity values $I$ of $Z_{\mathrm{DR}} / K_{\mathrm{DP}}$ data saved as tiff images one volume at a time [Eq. (A1)]. This is done to find the best possible estimate of mean $\hat{\mu}$ and standard deviation $\hat{\sigma}$ and restrict the intensity range as per [Eq. (A2)]. Parameters $a$ and $b$ are automatically calculated by the algorithm. Cutting off range as per last step adjusts the image contrast by suppressing extremely low/high intensities. Next, intensity values are normalized to map dynamic range of intensity across different times to a common range of 0 to 1 [Eq. (A3)]. Finally, a two-dimensional Gaussian filter is used to remove any unwanted noise in intensity values. This is done by calculating a weighted average of intensity values from a pixel's neighborhood [Eqs. (A4) and (A5)]:

$$
\begin{aligned}
& I:\left\{\mathbb{X} \subseteq \mathbb{R}^{3}\right\} \rightarrow\min , \ldots, \max \} \text { fit Gaussian distribution } \\
& \text { and calculate } \hat{\mu} \text { and } \hat{\sigma} \text { of } I, \\
& I^{\prime} \in[\hat{\mu}-a \times \hat{\sigma}, \hat{\mu}+b \times \hat{\sigma}], \text { normalize } I^{\prime} \text { to obtain } I_{N} \ni, \\
& I_{N}:\left\{\mathbb{X} \subseteq \mathbb{R}^{3}\right\} \rightarrow[0,1] \text { smoothing each horizontal slice, } i,
\end{aligned}
$$



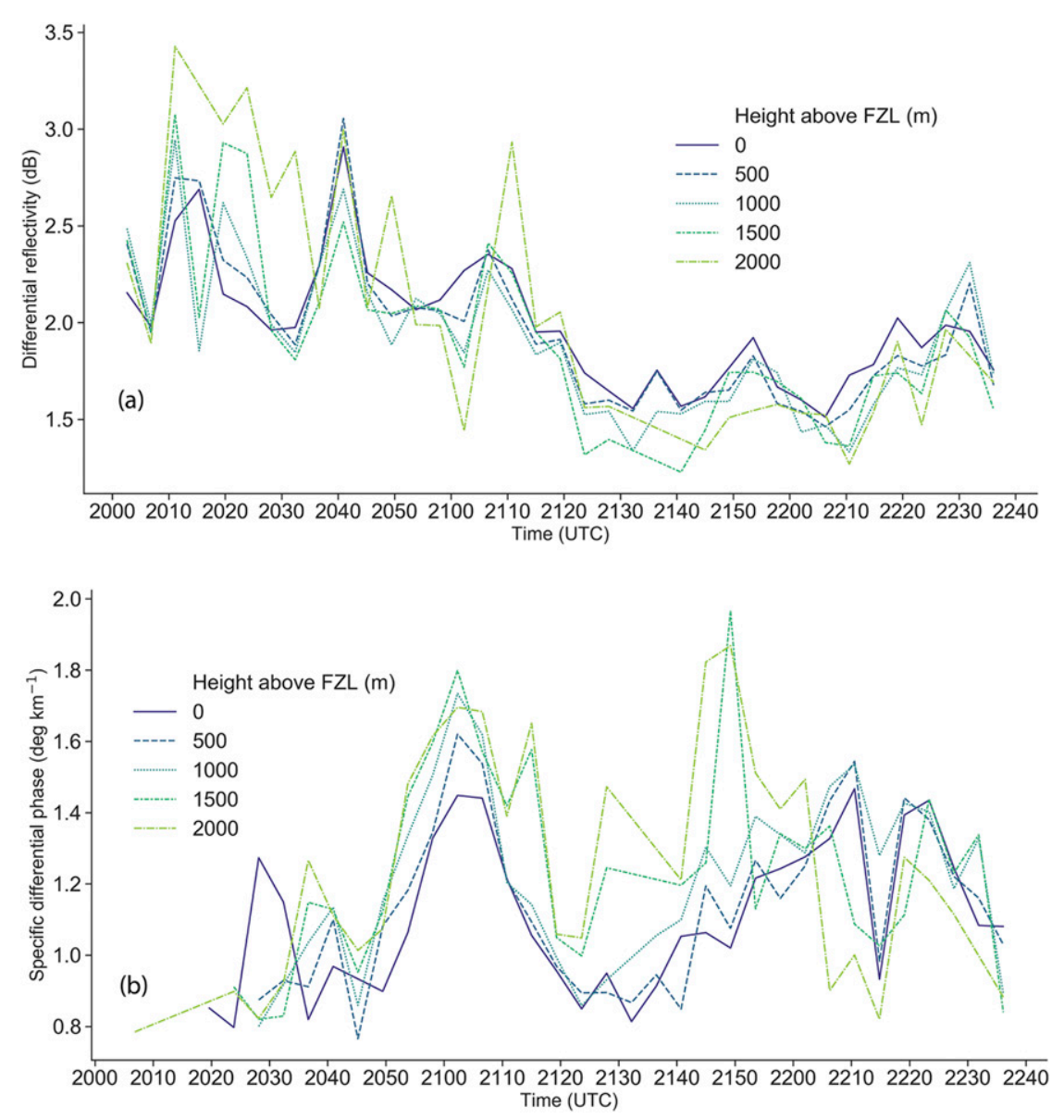

FIG. A2. (a) Time series of $Z_{\mathrm{DR}}$ values from within segmented $Z_{\mathrm{DR}}$ column objects at $0,0.5$, $1,1.5$, and $2 \mathrm{~km}$ above the environmental melting level. (b) As in (a), but for $K_{\mathrm{DP}}$ values within segmented $K_{\mathrm{DP}}$ objects.

$I_{S}=\omega I_{N}^{i}$ using a 2D Gaussian convolution filter,

$$
=\sum_{d x=-a}^{a} \sum_{d y=-b}^{b} \omega(d x, d y) I_{N}^{i}(x+d x, y+d y) .
$$

Further details of steps involved and parameter values used in image segmentation of $Z_{\mathrm{DR}}$ and $K_{\mathrm{DP}}$ columns are provided in Table A2.

\section{b. $Z_{D R}$ and $K_{D P}$ values in identified column objects}

Previous studies have found the width and height of $Z_{\mathrm{DR}}$ and $K_{\mathrm{DP}}$ columns (like shown in Fig. A1) to be proportional to the sizes of updrafts (Kumjian et al. 2014; Snyder et al. 2017). Therefore, not all identified objects correspond to the same updraft intensity. This is further illustrated in Fig. A2 wherein a time series of mean $Z_{\mathrm{DR}}$ and $K_{\mathrm{DP}}$ values in corresponding column objects is plotted for different heights at and above melting level. Mean $Z_{\mathrm{DR}}$ values of $>3 \mathrm{~dB}$ were present at least $2 \mathrm{~km}$ above the melting level prior to 2110 UTC. Soon after, the trend reversed and the values at higher altitudes plummeted to $<1.5 \mathrm{~dB}$ (Fig. A2a). This is in agreement with the trend of reduced $Z_{\mathrm{DR}}$ column volume around the same time which was inferred as a consequence of weaker updrafts unable to reach higher altitudes in the storm (Fig. 17c). The mean $Z_{\mathrm{DR}}$ values found in this analysis are certainly representative of the observed $Z_{\mathrm{DR}}$ values in severe storms [cf. Figs. 3c and 4c in Kuster et al. (2020)].

TABLE A1. Retrieval of $K_{\mathrm{DP}}$ field for KTLX radar data using LP phase processing per implementation of Giangrande et al. (2013) in PyART function "pyart.correct.phase_proc_lp."

\begin{tabular}{|c|c|c|}
\hline $\begin{array}{c}\text { Parameter } \\
\text { name }\end{array}$ & Parameter definition & $\begin{array}{c}\text { Parameter } \\
\text { value }\end{array}$ \\
\hline Offset & Reflectivity offset in $\mathrm{dB} Z$ & 0 \\
\hline self_const & Self-consistency factor & 60000 \\
\hline low_z & $\begin{array}{l}\text { Low limit for reflectivity: reflectivity } \\
<\text { low_z set to low_z }\end{array}$ & 25 \\
\hline high_z & $\begin{array}{l}\text { High limit for reflectivity: reflectivity } \\
>\text { high } \_z=\text { high_z }\end{array}$ & 53 \\
\hline min_phidp & Min differential phase & 0.01 \\
\hline min_ncp & Min normal coherent power & 0.5 \\
\hline min_rhv & Min copolar coefficient & 0.8 \\
\hline Fzl & Level of environmental freezing level & 4200 \\
\hline window_len & $\begin{array}{l}\text { Length of Sobel window applied to } \\
\phi_{\mathrm{DP}} \text { prior to calculating } \mathrm{K}_{\mathrm{DP}}\end{array}$ & 35 \\
\hline Coef & $\begin{array}{l}\text { Exponent linking } Z \text { to } K_{\mathrm{DP}} \text { in self } \\
\text { consistency }\end{array}$ & 0.914 \\
\hline
\end{tabular}


TABLE A2. Order of steps followed and thresholds used for image segmentation of $Z_{\mathrm{DR}}$ and $K_{\mathrm{DP}}$ column objects.

\begin{tabular}{|c|c|c|c|}
\hline Segmentation step & Substep & Parameters required & Parameter value \\
\hline Preprocessing [refer to Eqs. (A1)-(A5)] & Gaussian smoothing & Standard deviation & 1 \\
\hline \multirow[t]{9}{*}{ Core segmentation algorithm } & 3D spot filter & [scale_x,cutoff_x] & $\begin{array}{c}{[1.25,0.05]} \\
{[1.15,0.9]}\end{array}$ \\
\hline & & hole_min & 100 \\
\hline & & hole_max & 100000 \\
\hline & 2D filament filter & [scale_x,cutoff_x] & {$[1.25,0.07]$} \\
\hline & & hole_min & 100 \\
\hline & & hole_max & 100000 \\
\hline & Watershed segmentation & min_size & 50 \\
\hline & & connectivity & 1 \\
\hline & & min_distance & 2 \\
\hline \multirow[t]{2}{*}{ Postprocessing } & remove_small_objects & min_size & 3500 \\
\hline & & connectivity & 1 \\
\hline
\end{tabular}

Mean $K_{\mathrm{DP}}$ values have a noticeably different pattern than mean $Z_{\mathrm{DR}}$ values (Fig. A2b). Similar to the abrupt behavior of $K_{\text {DP }}$ column volume, we cannot explain this difference without any in situ microphysical data. Previous studies have agreed that $K_{\mathrm{DP}}$ columns are usually found on the western periphery of updraft (Loney et al. 2002; Kumjian and Ryzhkov 2008). Moreover, $K_{\mathrm{DP}}$ tends to be directly proportional to $q_{r}$ (rain mixing ratio) and the increased $K_{\mathrm{DP}}$ values at the column top are associated with an increasing number of small-to-moderate hailstones with significant water fraction (Snyder et al. 2017). Therefore, it is possible that although the underlying microphysical processes of formation of $Z_{\mathrm{DR}}$ and $K_{\mathrm{DP}}$ columns are influenced by the updraft intensity but the enhanced values at column top and not necessarily linked to actual updraft strength in case of $K_{\mathrm{DP}}$ columns. Another possibility is that the algorithm we use for $K_{\mathrm{DP}}$ calculations is not well suited for processing of differential phase in the mixed-phase region. It is also likely that $K_{\mathrm{DP}}$ columns in this particular case are not good indicators of updraft intensity especially when we may have too many hailstones undergoing wet growth.

\section{APPENDIX B}

\section{Radar Analysis Procedures}

\section{Hydrometeor identification (HID) procedures}

The National Center for Atmospheric Research (NCAR) PID algorithm (Vivekanandan et al. 1999) available in RadX software package (available at https://doi.org/10.5065/ 60hz-ry38) was used to obtain hydrometeor classification for KTLX data (Fig. B1). The PID algorithm uses fuzzy logic to estimate the bulk hydrometeor category based on membership functions created from statistics of observed distribution of dual pol variables $\left(Z_{H}, Z_{\mathrm{DR}}, \rho_{\mathrm{hv}}\right.$, and $\left.K_{\mathrm{DP}}\right)$ for each class. RadxPid program was used to retrieve PID categories in polar coordinates which were subsequently gridded in $3 \mathrm{D}$ Cartesian coordinates using Radx2Grid program. The size and extent of PID grid was identical to grids created for flash products. RadxPID requires three input parameter files for performing PID analysis: main parameter file, $K_{\mathrm{DP}}$-specific parameter file, and PID-specific parameter file. Default values corresponding to S-band radars were used for $K_{\mathrm{DP}}$ and PID parameter files in this analysis. The 1800 UTC sounding data from OUN was used as an additional input in the PID-specific file.
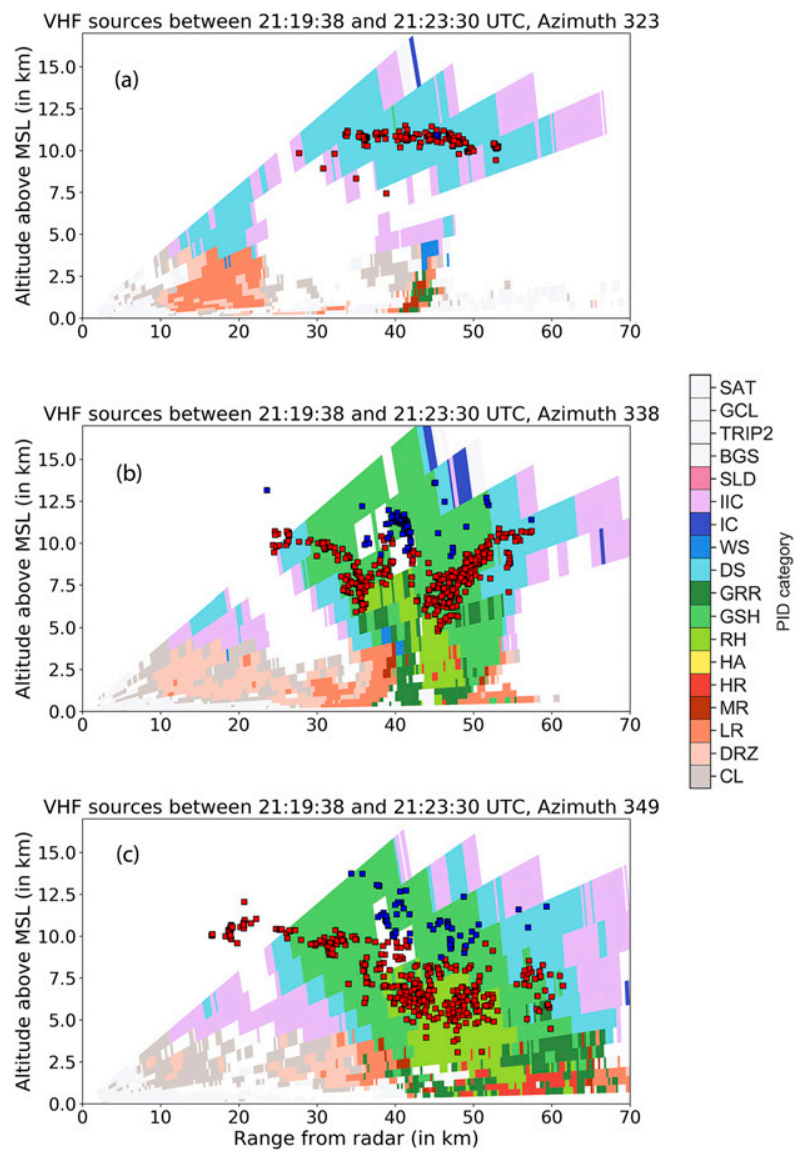

FIG. B1. (a)-(c) Psuedo-RHI plots of bulk hydrometeor categories identified using NCAR PID algorithm at the same azimuths as used in Fig. 15. Only the VHF sources within $500 \mathrm{~m}$ of the azimuth are overlaid to illustrate the charge structure. Descending pattern of positive polarity VHF sources in (c) lie within the region classified as GSH (mixture of graupel and small hail) and $\mathrm{RH}$ (mixture of rain and hail). 


\section{REFERENCES}

Askelson, M. A., J.-P. Aubagnac, and J. M. Straka, 2000: An adaptation of the Barnes filter applied to the objective analysis of radar data. Mon. Wea. Rev., 128, 3050-3082, https://doi.org/ 10.1175/1520-0493(2000)128<3050:AAOTBF>2.0.CO;2.

Baker, B., M. B. Baker, E. R. Jayaratne, J. Latham, and C. P. R. Saunders, 1987: The influence of diffusional growth rates on the charge transfer accompanying rebounding collisions between ice crystals and soft hailstones. Quart. J. Roy. Meteor. Soc., 113, 1193-1215, https://doi.org/10.1002/qj.49711347807.

Barnes, S. L., 1964: A technique for maximizing details in numerical weather map analysis. J. Appl. Meteor., 3, 396-409, https://doi.org/ 10.1175/1520-0450(1964)003<0396:ATFMDI > 2.0.CO;2.

Berdeklis, P., and R. List, 2001: The ice crystal-graupel collision charging mechanism of thunderstorm electrification. J. Atmos. Sci., 58, 2751-2770, https://doi.org/10.1175/1520-0469(2001) $058<2751$ :TICGCC $>2.0$.CO 2 .

Bergeron, T., 1935: On the physics of clouds and precipitation. Proc. Fifth Assembly UGGI, Lisbon, Portugal, UGGI, 156-180.

Betz, H., U. Schumann, and P. Laroche, Eds., 2008: Lightning: Principles, Instruments and Applications: Review of Modern Lightning Research. Springer, $641 \mathrm{pp}$.

Biagi, C. J., K. L. Cummins, K. E. Kehoe, and E. P. Krider, 2007: National Lightning Detection Network (NLDN) performance in southern Arizona, Texas, and Oklahoma in 20032004. J. Geophys. Res., 112, D05208, https://doi.org/10.1029/ 2006JD007341.

Bluestein, H. B., and D. R. MacGorman, 1998: Evolution of cloudto-ground lightning characteristics and storm structure in the Spearman, Texas, tornadic supercells of 31 May 1990. Mon. Wea. Rev., 126, 1451-1467, https://doi.org/10.1175/15200493(1998)126<1451:EOCTGL>2.0.CO;2.

Brandes, E. A., 1978: Mesocyclone evolution and tornadogenesis: Some observations. Mon. Wea. Rev., 106, 995-1011, https:// doi.org/10.1175/1520-0493(1978)106<0995:MEATSO >2.0.CO;2.

— , J. Vivekanandan, J. D. Tuttle, and C. J. Kessinger, 1995: A study of thunderstorm microphysics with multiparameter radar and aircraft observations. Mon. Wea. Rev., 123,3129-3143, https:// doi.org/10.1175/1520-0493(1995)123<3129:ASOTMW>2.0.CO;2.

Bringi, V. N., L. Liu, P. C. Kennedy, V. Chandrasekar, and S. A. Rutledge, 1996: Dual multiparameter radar observations of intense convective storms: The 24 June 1992 case study. Meteor. Atmos. Phys., 59, 3-31, https://doi.org/10.1007/BF01031999.

—, K. Knupp, A. Detwiler, L. Liu, I. J. Caylor, and R. A. Black, 1997: Evolution of a Florida thunderstorm during the convection and precipitation/electrification experiment: The case of 9 August 1991. Mon. Wea. Rev., 125, 2131-2160, https://doi.org/ 10.1175/1520-0493(1997)125<2131:EOAFTD>2.0.CO;2.

Brock, F. V., K. C. Crawford, R. L. Elliott, G. W. Cuperus, S. J. Stadler, H. L. Johnson, and M. D. Eilts, 1995: The Oklahoma Mesonet: A technical overview. J. Atmos. Oceanic Technol., 12, 5-19, https:// doi.org/10.1175/1520-0426(1995)012<0005:TOMATO>2.0.CO;2.

Bruning, E. C., and D. R. MacGorman, 2013: Theory and observations of controls on lightning flash size spectra. J. Atmos. Sci., 70, 4012-4029, https://doi.org/10.1175/JAS-D-12-0289.1.

- W. D. Rust, D. R. MacGorman, M. I. Biggerstaff, and T. J. Schuur, 2010: formation of charge structures in a supercell. Mon. Wea. Rev., 138, 3740-3761, https://doi.org/10.1175/ 2010MWR3160.1.

— S. A. Weiss, and K. M. Calhoun, 2014: Continuous variability in thunderstorm primary electrification and an evaluation of inverted-polarity terminology. Atmos. Res., 135-136, 274-284, https://doi.org/10.1016/j.atmosres.2012.10.009.
— stationary lightning mapper. J. Geophys. Res. Atmos., 124, 14 285-14 309, https://doi.org/10.1029/2019JD030874.

Calhoun, K. M., D. R. MacGorman, C. L. Ziegler, and M. I. Biggerstaff, 2013: Evolution of lightning activity and storm charge relative to dual-Doppler analysis of a high-precipitation supercell storm. Mon. Wea. Rev., 141, 2199-2223, https:// doi.org/10.1175/MWR-D-12-00258.1.

Carbone, R. E., M. J. Carpenter, and C. D. Burghart, 1985: Doppler radar sampling limitations in convective storms. J. Atmos. Oceanic Technol., 2, 357-361, https://doi.org/10.1175/15200426(1985)002<0357:DRSLIC $>2.0$.CO;2.

Carey, L. D., and S. A. Rutledge, 1996: A multiparameter radar case study of the microphysical and kinematic evolution of a lightning producing storm. Meteor. Atmos. Phys., 59, 33-64, https://doi.org/10.1007/BF01032000.

$\longrightarrow$, and - 1998: Electrical and multiparameter radar observations of a severe hailstorm. J. Geophys. Res., 103, 13979 14 000, https://doi.org/10.1029/97JD02626.

- , and ——, 2000: The relationship between precipitation and lightning in tropical island convection: A C-band polarimetric radar study. Mon. Wea. Rev., 128, 2687-2710, https://doi.org/10.1175/1520-0493(2000)128<2687:TRBPAL > 2.0.CO;2.

, and K. M. Buffalo, 2007: Environmental control of cloud-toground lightning polarity in severe storms. Mon. Wea. Rev., 135, 1327-1353, https://doi.org/10.1175/MWR3361.1.

_- W. A. Petersen, and S. A. Rutledge, 2003: Evolution of cloud-to-ground lightning and storm structure in the Spencer, South Dakota, tornadic supercell of 30 May 1998. Mon. Wea. Rev., 131, 1811-1831, https://doi.org/10.1175// 2566.1.

— E. V. Schultz, C. J. Schultz, W. Deierling, W. A. Petersen, A. L. Bain, and K. E. Pickering, 2019: An evaluation of relationships between radar-inferred kinematic and microphysical parameters and lightning flash rates in Alabama storms. Atmosphere, 10, 796, https://doi.org/10.3390/atmos10120796.

Caswell, T. A., and Coauthors, 2019: matplotlib/matplotlib v3.1.2. Zenodo, accessed 18 December 2019, https://doi.org/10.5281/ zenodo. 3563226 .

Caylor, I. J., and A. J. Illingworth, 1987: Radar observations and modelling of warm rain initiation. Quart. J. Roy. Meteor. Soc., 113, 1171-1191, https://doi.org/10.1002/qj.49711347806.

Chen, J., L. Ding, M. P. Viana, M. C. Hendershott, R. Yang, I. A. Mueller, and S. M. Rafelski, 2018: The Allen cell structure segmenter: A new open source toolkit for segmenting 3D intracellular structures in fluorescence microscopy images. bioRxiv, https://doi.org/10.1101/491035.

Chmielewski, V. C., and E. C. Bruning, 2016: Lightning Mapping Array flash detection performance with variable receiver thresholds. J. Geophys. Res. Atmos., 121, 8600-8614, https:// doi.org/10.1002/2016JD025159.

,-- , and B. C. Ancell, 2018: Variations of thunderstorm charge structures in West Texas on 4 June 2012. J. Geophys. Res. Atmos., 123, 9502-9523, https://doi.org/10.1029/2018JD029006.

Chronis, T., L. D. Carey, C. J. Schultz, E. V. Schultz, K. M. Calhoun, and S. J. Goodman, 2015: Exploring lightning jump characteristics. Wea. Forecasting, 30, 23-37, https://doi.org/ 10.1175/WAF-D-14-00064.1.

Coleman, L. M., T. C. Marshall, M. Stolzenburg, T. Hamlin, P. R. Krehbiel, W. Rison, and R. J. Thomas, 2003: Effects of charge and electrostatic potential on lightning propagation. J. Geophys. Res., 108, 4298, https://doi.org/10.1029/2002JD002718. 
Cumming, G., 2013: Understanding the New Statistics: Effect Sizes, Confidence Intervals, and Meta-Analysis. Multivariate Applications Series, Taylor \& Francis, 536 pp.

Cummins, K. L., and M. J. Murphy, 2009: An overview of lightning locating systems: History, techniques, and data uses, with an indepth look at the U.S. NLDN. IEEE Trans. Electromagn. Compat., 51, 499-518, https://doi.org/10.1109/TEMC.2009.2023450.

— E. P. Krider, and M. D. Malone, 1998: The U.S. National Lightning Detection Network and applications of cloud-to-ground lightning data by electric power utilities. IEEE Trans. Electromagn. Compat., 40, 465-480, https://doi.org/10.1109/15.736207.

Curran, E. B., and W. D. Rust, 1992: Positive ground flashes produced by low-precipitation thunderstorms in Oklahoma on 26 April 1984. Mon. Wea. Rev., 120, 544-553, https://doi.org/ 10.1175/1520-0493(1992)120<0544:PGFPBL>2.0.CO;2.

Darden, C. B., D. J. Nadler, B. C. Carcione, R. J. Blakeslee, G. T. Stano, and D. E. Buechler, 2010: Utilizing total lightning information to diagnose convective trends. Bull. Amer. Meteor. Soc., 91, 167-176, https://doi.org/10.1175/2009BAMS2808.1.

Dash, J. G., B. L. Mason, and J. S. Wettlaufer, 2001: Theory of charge and mass transfer in ice-ice collisions. J. Geophys. Res., 106, 20 395-20 402, https://doi.org/10.1029/2001JD900109.

Dawson, D. T., E. R. Mansell, and M. R. Kumjian, 2015: Does wind shear cause hydrometeor size sorting? J. Atmos. Sci., 72, 340348, https://doi.org/10.1175/JAS-D-14-0084.1.

deeplycloudy, 2015: lmatools: lmatools-v0.5z-stable. Zenodo, accessed 22 January 2018, https://doi.org/10.5281/zenodo.32510.

Deierling, W., and W. A. Petersen, 2008: Total lightning activity as an indicator of updraft characteristics. J. Geophys. Res., 113, D16210, https://doi.org/10.1029/2007JD009598.

,-- J. Latham, S. Ellis, and H. J. Christian, 2008: The relationship between lightning activity and ice fluxes in thunderstorms. J. Geophys. Res., 113, D15210, https://doi.org/ 10.1029/2007JD009700.

Emersic, C., and C. P. R. Saunders, 2010: Further laboratory investigations into the Relative Diffusional Growth Rate theory of thunderstorm electrification. Atmos. Res., 98, 327-340, https://doi.org/10.1016/j.atmosres.2010.07.011.

_ , P. L. Heinselman, D. R. MacGorman, and E. C. Bruning, 2011: Lightning activity in a hail-producing storm observed with phased-array radar. Mon. Wea. Rev., 139, 1809-1825, https://doi.org/10.1175/2010MWR3574.1.

Ester, M., H.-P. Kriegel, J. Sander, and X. Xu, 1996: A densitybased algorithm for discovering clusters in large spatial databases with noise. Proc. Second Int. Conf. on Knowledge Discovery and Data Mining, Portland, OR, AAAI Press, 226-231.

Farnell, C., T. Rigo, and N. Pineda, 2017: Lightning jump as a nowcast predictor: Application to severe weather events in Catalonia. Atmos. Res., 183, 130-141, https://doi.org/10.1016/ j.atmosres.2016.08.021.

Findeisen, W., 1938: Kolloid-meteorologische Vorgänge bei Neiderschlags-bildung. Meteor. Z., 55, 121-133.

Fleenor, S. A., C. J. Biagi, K. L. Cummins, E. P. Krider, and X.-M. Shao, 2009: Characteristics of cloud-to-ground lightning in warmseason thunderstorms in the Central Great Plains. Atmos. Res., 91, 333-352, https://doi.org/10.1016/j.atmosres.2008.08.011.

Fuchs, B. R., E. C. Bruning, S. A. Rutledge, L. D. Carey, P. R. Krehbiel, and W. Rison, 2016: Climatological analyses of LMA data with an open-source lightning flash-clustering algorithm. J. Geophys. Res. Atmos., 121, 8625-8648, https:// doi.org/10.1002/2015JD024663.

_ S. A. Rutledge, B. Dolan, L. D. Carey, and C. Schultz, 2018: Microphysical and kinematic processes associated with anom- alous charge structures in isolated convection. J. Geophys. Res. Atmos., 123, 6505-6528, https://doi.org/10.1029/2017JD027540.

Gatlin, P. N., and S. J. Goodman, 2010: A total lightning trending algorithm to identify severe thunderstorms. J. Atmos. Oceanic Technol., 27, 3-22, https://doi.org/10.1175/2009JTECHA1286.1.

Giangrande, S. E., R. McGraw, and L. Lei, 2013: An application of linear programming to polarimetric radar differential phase processing. J. Atmos. Oceanic Technol., 30, 1716-1729, https:// doi.org/10.1175/JTECH-D-12-00147.1.

Goodman, S. J., D. E. Buechler, P. D. Wright, and W. D. Rust, 1988: Lightning and precipitation history of a microburstproducing storm. Geophys. Res. Lett., 15, 1185-1188, https:// doi.org/10.1029/GL015i011p01185.

Hall, M. P. M., J. W. F. Goddard, and S. M. Cherry, 1984: Identification of hydrometeors and other targets by dualpolarization radar. Radio Sci., 19, 132-140, https://doi.org/ 10.1029/RS019i001p00132.

Hallett, J., and S. C. Mossop, 1974: Production of secondary ice particles during the riming process. Nature, 249, 26-28, https:// doi.org/10.1038/249026a0.

Harris, C. R., and Coauthors, 2020: Array programming with NumPy. Nature, 585, 357-362, https://doi.org/10.1038/s41586020-2649-2.

Herzegh, P. H., and A. R. Jameson, 1992: Observing precipitation through dual-polarization radar measurements. Bull. Amer. Meteor. Soc., 73, 1365-1376, https://doi.org/10.1175/15200477(1992)073<1365:OPTDPR>2.0.CO;2.

Heymsfield, A. J., 1978: The characteristics of graupel particles in northeastern Colorado cumulus congestus clouds. J. Atmos. Sci., 35, 284-295, https://doi.org/10.1175/1520-0469(1978) $035<0284$ :TCOGPI $>2.0$. CO 2 .

Hoyer, S., and Coauthors, 2019: pydata/xarray v0.14.1. Zenodo, accessed 19 November 2019, https://doi.org/10.5281/ zenodo. 3547868 .

Hubbert, J., V. N. Bringi, L. D. Carey, and S. Bolen, 1998: CSUCHILL polarimetric radar measurements from a severe hail storm in eastern Colorado. J. Appl. Meteor., 37, 749-775, https:// doi.org/10.1175/1520-0450(1998)037<0749:CCPRMF>2.0.CO;2.

Hunter, J. D., 2007: Matplotlib: A 2D graphics environment. Comput. Sci. Eng., 9, 90-95, https://doi.org/10.1109/MCSE.2007.55.

Illingworth, A. J., J. W. F. Goddard, and S. M. Cherry, 1987: Polarization radar studies of precipitation development in convective storms. Quart. J. Roy. Meteor. Soc., 113, 469-489, https://doi.org/10.1002/qj.49711347604.

Jameson, A. R., M. J. Murphy, and E. P. Krider, 1996: Multiple-parameter radar observations of isolated Florida thunderstorms during the onset of electrification. J. Appl. Meteor., 35, 343-354, https://doi.org/ 10.1175/1520-0450(1996)035<0343:MPROOI > 2.0.CO;2.

Johnson, E., and E. Mansell, 2006: Three dimensional lightning mapping of the central Oklahoma supercell on 26 May 2004. Second Conf. on Meteorological Applications of Lightning Data, Atlanta, GA, Amer. Meteor. Soc., 6.5, https://ams.confex.com/ ams/Annual2006/techprogram/paper_104352.htm.

Kasemir, H. W., 1960: A contribution to the electrostatic theory of a lightning discharge. J. Geophys. Res., 65, 1873-1878, https://doi.org/10.1029/JZ065i007p01873.

Knapp, D., 1994: Using cloud-to-ground lightning data to identify tornadic thunderstorm signatures and nowcast severe weather. Natl. Wea. Dig., 19, 35-42.

Kosiba, K., J. Wurman, Y. Richardson, P. Markowski, P. Robinson, and J. Marquis, 2013: Genesis of the Goshen County, Wyoming, tornado on 5 June 2009 during VORTEX2. Mon. Wea. Rev., 141, 1157-1181, https://doi.org/10.1175/MWR-D-12-00056.1. 
Kumjian, M. R., and A. V. Ryzhkov, 2008: Polarimetric signatures in supercell thunderstorms. J. Appl. Meteor. Climatol., 47, 1940-1961, https://doi.org/10.1175/2007JAMC1874.1.

— — _ , V. M. Melnikov, and T. J. Schuur, 2010: Rapid-scan super-resolution observations of a cyclic supercell with a dualpolarization WSR-88D. Mon. Wea. Rev., 138, 3762-3786, https://doi.org/10.1175/2010MWR3322.1.

—_, A. P. Khain, N. Benmoshe, E. Ilotoviz, A. V. Ryzhkov, and V. T. J. Phillips, 2014: The anatomy and physics of ZDR columns: Investigating a polarimetric radar signature with a spectral bin microphysical model. J. Appl. Meteor. Climatol., 53, 1820-1843, https://doi.org/10.1175/JAMC-D-13-0354.1.

Kuster, C. M., T. J. Schuur, T. T. Lindley, and J. C. Snyder, 2020: Using ZDR columns in forecaster conceptual models and warning decision-making. Wea. Forecasting, 35, 2507-2522, https://doi.org/10.1175/WAF-D-20-0083.1.

Lang, T. J., and S. A. Rutledge, 2002: Relationships between convective storm kinematics, precipitation, and lightning. Mon. Wea. Rev., 130, 2492-2506, https://doi.org/10.1175/15200493(2002)130<2492:RBCSKP > 2.0.CO;2.

— , and Coauthors, 2004: The Severe Thunderstorm Electrification and Precipitation Study. Bull. Amer. Meteor. Soc., 85, 11071126, https://doi.org/10.1175/BAMS-85-8-1107.

Latham, J., and J. E. Dye, 1989: Calculations on the electrical development of a small thunderstorm. J. Geophys. Res., 94, 13141-13 144, https://doi.org/10.1029/JD094iD11p13141.

— W. A. Petersen, W. Deierling, and H. J. Christian, 2007: Field identification of a unique globally dominant mechanism of thunderstorm electrification. Quart. J. Roy. Meteor. Soc., 133, 1453-1457, https://doi.org/10.1002/qj.133.

Lemon, L. R., and C. A. Doswell, 1979: Severe thunderstorm evolution and mesocyclone structure as related to tornadogenesis. Mon. Wea. Rev., 107, 1184-1197, https://doi.org/ 10.1175/1520-0493(1979)107<1184:STEAMS>2.0.CO;2.

Lier-Walqui, M., and Coauthors, 2016: On polarimetric radar signatures of deep convection for model evaluation: Columns of specific differential phase observed during MC3E. Mon. Wea. Rev., 144, 737-758, https://doi.org/10.1175/MWR-D-150100.1 .

Loney, M. L., D. S. Zrnić, J. M. Straka, and A. V. Ryzhkov, 2002: Enhanced polarimetric radar signatures above the melting level in a supercell storm. J. Appl. Meteor., 41, 1179-1194, https:// doi.org/10.1175/1520-0450(2002)041<1179:EPRSAT>2.0.CO;2.

Lund, N. R., D. R. MacGorman, T. J. Schuur, M. I. Biggerstaff, and W. D. Rust, 2009: Relationships between lightning location and polarimetric radar signatures in a small mesoscale convective system. Mon. Wea. Rev., 137, 4151-4170, https:// doi.org/10.1175/2009MWR2860.1.

MacGorman, D. R., and D. W. Burgess, 1994: Positive cloud-toground lightning in tornadic storms and hailstorms. Mon. Wea. Rev., 122, 1671-1697, https://doi.org/10.1175/1520-0493(1994) 122<1671:PCTGLI >2.0.CO;2.

,,-- V. Mazur, W. D. Rust, W. L. Taylor, and B. C. Johnson, 1989: Lightning rates relative to tornadic storm evolution on 22 May 1981. J. Atmos. Sci., 46, 221-251, https://doi.org/ 10.1175/1520-0469(1989)046<0221:LRRTTS>2.0.CO;2.

— W. D. Rust, P. Krehbiel, W. Rison, E. Bruning, and K. Wiens, 2005: The electrical structure of two supercell storms during STEPS. Mon. Wea. Rev., 133, 2583-2607, https://doi.org/ 10.1175/MWR2994.1.

— , and Coauthors, 2008: TELEX: The Thunderstorm Electrification and Lightning Experiment. Bull. Amer. Meteor. Soc., 89, 997-1014, https://doi.org/10.1175/2007BAMS2352.1.
— I. R. Apostolakopoulos, N. R. Lund, N. W. S. Demetriades, M. J. Murphy, and P. R. Krehbiel, 2011: The timing of cloudto-ground lightning relative to total lightning activity. Mon. Wea. Rev., 139, 3871-3886, https://doi.org/10.1175/MWR-D11-00047.1.

—, M. S. Elliott, and E. DiGangi, 2017: Electrical discharges in the overshooting tops of thunderstorms. J. Geophys. Res. Atmos., 122, 2929-2957, https://doi.org/10.1002/2016JD025933.

Majcen, M., P. Markowski, Y. Richardson, D. Dowell, and J. Wurman, 2008: Multipass objective analyses of Doppler radar data. J. Atmos. Oceanic Technol., 25, 1845-1858, https:// doi.org/10.1175/2008JTECHA1089.1.

Mansell, E. R., D. R. MacGorman, C. L. Ziegler, and J. M. Straka, 2002: Simulated three-dimensional branched lightning in a numerical thunderstorm model. J. Geophys. Res., 107, 4075, https://doi.org/10.1029/2000JD000244.

Marshall, T. C., and W. D. Rust, 1991: Electric field soundings through thunderstorms. J. Geophys. Res., 96, 22 297-22306, https://doi.org/10.1029/91JD02486.

May, R. M., S. C. Arms, P. Marsh, E. Bruning, J. R. Leeman, K. Goebbert, J. E. Thielen, and Z. S. Bruick, 2020: Metpy: A Python package for meteorological data. Unidata, accessed 11 March 2020, https://doi.org/10.5065/D6WW7G29.

Mazur, V., and L. H. Ruhnke, 1993: Common physical processes in natural and artificially triggered lightning. J. Geophys. Res., 98, 12 913-12 930, https://doi.org/10.1029/93JD00626.

McDonald, J. R., and K. C. Mehta, 2006: A recommendation for an Enhanced Fujita scale (EF-Scale). Texas Tech University Tech. Rep., 95 pp.

McPherson, R. A., and Coauthors, 2007: Statewide monitoring of the mesoscale environment: A technical update on the Oklahoma mesonet. J. Atmos. Oceanic Technol., 24, 301-321, https://doi.org/10.1175/JTECH1976.1.

Mecikalski, R. M., A. L. Bain, and L. D. Carey, 2015: Radar and lightning observations of deep moist convection across northern Alabama during DC3: 21 May 2012. Mon. Wea. Rev., 143, 2774-2794, https://doi.org/10.1175/MWR-D-14-00250.1.

Metzger, E., and W. A. Nuss, 2013: The relationship between total cloud lightning behavior and radar-derived thunderstorm structure. Wea. Forecasting, 28, 237-253, https://doi.org/10.1175/ WAF-D-11-00157.1.

Miller, P., A. Ellis, and S. Keighton, 2015: The utility of total lightning trends in diagnosing single-cell thunderstorm severity: Examples from the central Appalachians region. J. Oper. Meteor., 3, 82-98, https://doi.org/10.15191/nwajom.2015.0308.

Murphy, M., 2017: Preliminary results from the inclusion of lightning type and polarity in the identification of severe storms. Eighth Conf. on the Meteorological Application of Lightning Data, Seattle, WA, Amer. Meteor. Soc., 7.3, https://ams.confex.com/ ams/97Annual/webprogram/Paper308037.html.

_ , J. A. Cramer, and R. K. Said, 2021: Recent history of upgrades to the U.S. national lightning detection network. J. Atmos. Oceanic Technol., 38, 573-585, https://doi.org/ 10.1175/JTECH-D-19-0215.1.

Nag, A., M. J. Murphy, K. L. Cummins, A. E. Pifer, and J. A. Cramer, 2014: Recent evolution of the U.S. national lightning detection network. 23rd Int. Lightning Detection Conf., Tucson, AZ, Vaisala Inc., 6.

NOAA National Weather Service (NWS) Radar Operations Center, 1991: NOAA Next Generation Radar (NEXRAD) Level 2 Base Data. [KTLX]. NOAA National Centers for Environmental Information, accessed 20 January 2020, https:// doi.org/10.7289/V5W9574V. 
Office of the Federal Coordinator for Meteorology, 2016: WSR88D meteorological observations. Part A: System concepts, responsibilities, and procedures. Federal Meteorological Handbook 11, Office of the Federal Coordinator for Meteorology, $25 \mathrm{pp}$.

Orville, R. E., 2008: Development of the National Lightning Detection Network. Bull. Amer. Meteor. Soc., 89, 180-190, https://doi.org/10.1175/BAMS-89-2-180.

Payne, C. D., T. J. Schuur, D. R. MacGorman, M. I. Biggerstaff, K. M. Kuhlman, and W. D. Rust, 2010: Polarimetric and electrical characteristics of a lightning ring in a supercell storm. Mon. Wea. Rev., 138, 2405-2425, https://doi.org/ 10.1175/2009MWR3210.1.

Picca, J., M. Kumjian, and A. Ryzhkov, 2010: $Z_{D R}$ columns as a predictive tool for hail growth and storm evolution. 25th Conf. on Severe Local Storms, Denver, CO, Amer. Meteor. Soc., 11.3, https://ams.confex.com/ams/25SLS/techprogram/paper_ 175750.htm.

— J. Snyder, and A. Ryzhkov, 2015: An observational analysis of ZDR column trends in tornadic supercells. 37th Conf. on Radar Meteorology, Norman, OK, Amer. Meteor. Soc., 5A.5, https://ams.confex.com/ams/37RADAR/webprogram/ Paper275416.html.

Reinhart, B., and Coauthors, 2014: Understanding the relationships between lightning, cloud microphysics, and airborne radar-derived storm structure during Hurricane Karl (2010). Mon. Wea. Rev., 142, 590-605, https://doi.org/10.1175/MWR-D-13-00008.1.

Rison, W., R. J. Thomas, P. R. Krehbiel, T. Hamlin, and J. Harlin, 1999: A GPS-based three-dimensional lightning mapping system: Initial observations in central New Mexico. Geophys. Res. Lett., 26, 3573-3576, https://doi.org/10.1029/ 1999GL010856.

Rudlosky, S. D., and H. E. Fuelberg, 2013: Documenting storm severity in the mid-Atlantic region using lightning and radar information. Mon. Wea. Rev., 141, 3186-3202, https://doi.org/ 10.1175/MWR-D-12-00287.1.

—, S. J. Goodman, K. S. Virts, and E. C. Bruning, 2019: Initial Geostationary Lightning Mapper observations. Geophys. Res. Lett., 46, 1097-1104, https://doi.org/10.1029/2018GL081052.

Rust, W. D., and D. R. MacGorman, 2002: Possibly inverted-polarity electrical structures in thunderstorms during STEPS. Geophys. Res. Lett., 29, 1571, https://doi.org/10.1029/2001GL014303.

_ , and Coauthors, 2005: Inverted-polarity electrical structures in thunderstorms in the Severe Thunderstorm Electrification and Precipitation Study (STEPS). Atmos. Res., 76, 247-271, https://doi.org/10.1016/j.atmosres.2004.11.029.

Ryzhkov, A. V., and D. S. Zrnić, 1998: Polarimetric rainfall estimation in the presence of anomalous propagation. J. Atmos. Oceanic Technol., 15, 1320-1330, https://doi.org/10.1175/15200426(1998)015<1320:PREITP > 2.0.CO;2.

— 1st ed. Springer International Publishing, 486 pp., https:// doi.org/10.1007/978-3-030-05093-1.

Saunders, C. P. R., H. Bax-Norman, C. Emersic, E. E. Avila, and N. E. Castellano, 2006: Laboratory studies of the effect of cloud conditions on graupel/crystal charge transfer in thunderstorm electrification. Quart. J. Roy. Meteor. Soc., 132, 2653-2673, https://doi.org/10.1256/qj.05.218.

Schultz, C. J., W. A. Petersen, and L. D. Carey, 2009: Preliminary development and evaluation of lightning jump algorithms for the real-time detection of severe weather. J. Appl. Meteor. Climatol., 48, 2543-2563, https://doi.org/10.1175/2009JAMC2237.1.

,-- , and -2011 : Lightning and severe weather: A comparison between total and cloud-to-ground lightning trends. Wea. Forecasting, 26, 744-755, https://doi.org/10.1175/ WAF-D-10-05026.1.

_, L. D. Carey, E. V. Schultz, and R. J. Blakeslee, 2015: Insight into the kinematic and microphysical processes that control lightning jumps. Wea. Forecasting, 30, 1591-1621, https:// doi.org/10.1175/WAF-D-14-00147.1.

$-, \ldots,-$, and -2017 : Kinematic and microphysical significance of lightning jumps versus nonjump increases in total flash rate. Wea. Forecasting, 32, 275-288, https://doi.org/ 10.1175/WAF-D-15-0175.1.

Smith, P. L., D. J. Musil, A. G. Detwiler, and R. Ramachandran, 1999: Observations of mixed-phase precipitation within a CaPE thunderstorm. J. Appl. Meteor., 38, 145-155, https:// doi.org/10.1175/1520-0450(1999)038<0145:OOMPPW $>$ 2.0.CO 2 .

Snyder, J. C., A. V. Ryzhkov, M. R. Kumjian, A. P. Khain, and J. Picca, 2015: A $\mathrm{Z}_{\mathrm{DR}}$ column detection algorithm to examine convective storm updrafts. Wea. Forecasting, 30, 1819-1844, https://doi.org/10.1175/WAF-D-15-0068.1.

—, H. B. Bluestein, D. T. Dawson II, and Y. Jung, 2017: Simulations of polarimetric, $\mathrm{X}$-band radar signatures in supercells. Part II: ZDR columns and rings and KDP columns. J. Appl. Meteor. Climatol., 56, 2001-2026, https://doi.org/ 10.1175/JAMC-D-16-0139.1.

Sofroniew, N., and Coauthors, 2019: napari/napari: 0.2.7. Zenodo, accessed 7 April 2020, https://doi.org/10.5281/zenodo.3583440.

Soille, P., 2004: Morphological Image Analysis. Springer Berlin Heidelberg, 392 pp., https://doi.org/10.1007/978-3-662-05088-0.

SPC, 2013: Storm Prediction Center storm reports for 5/19/13. Accessed 27 June 2018, https://www.spc.noaa.gov/climo/reports/ 130519_rpts.html.

Steiger, S. M., R. E. Orville, and L. D. Carey, 2007: Total lightning signatures of thunderstorm intensity over North Texas. Part I: Supercells. Mon. Wea. Rev., 135, 3281-3302, https://doi.org/ 10.1175/MWR3472.1.

Stough, S. M., and L. D. Carey, 2020: Observations of anomalous charge structures in supercell thunderstorms in the southeastern United States. J. Geophys. Res. Atmos., 125, e2020JD033012, https://doi.org/10.1029/2020JD033012.

,-- C. J. Schultz, and P. M. Bitzer, 2017: Investigating the relationship between lightning and mesocyclonic rotation in supercell thunderstorms. Wea. Forecasting, 32, 2237-2259, https://doi.org/10.1175/WAF-D-17-0025.1.

Takahashi, T., 1978: Riming electrification as a charge generation mechanism in thunderstorms. J. Atmos. Sci., 35, 15361548, https://doi.org/10.1175/1520-0469(1978)035<1536: REAACG $>2.0 . \mathrm{CO} ; 2$.

— T. Tajiri, and Y. Sonoi, 1999: Charges on graupel and snow crystals and the electrical structure of winter thunderstorms. J. Atmos. Sci., 56, 1561-1578, https://doi.org/10.1175/15200469(1999)056<1561:COGASC $>2.0$. CO 2 .

Tessendorf, S. A., S. A. Rutledge, and K. C. Wiens, 2007: Radar and lightning observations of normal and inverted polarity multicellular storms from STEPS. Mon. Wea. Rev., 135, 36823706, https://doi.org/10.1175/2007MWR1954.1.

Thomas, R. J., P. R. Krehbiel, W. Rison, S. J. Hunyady, W. P. Winn, T. Hamlin, and J. Harlin, 2004: Accuracy of the lightning mapping array. J. Geophys. Res., 109, D14207, https:// doi.org/10.1029/2004JD004549.

Tian, Y., and Coauthors, 2019: Total lightning signatures of thunderstorms and lightning jumps in hailfall nowcasting in the Beijing area. Atmos. Res., 230, 104646, https://doi.org/10.1016/ j.atmosres.2019.104646. 
Trapp, R. J., 1999: Observations of nontornadic low-level mesocyclones and attendant tornadogenesis failure during VORTEX. Mon. Wea. Rev., 127, 1693-1705, https://doi.org/10.1175/15200493(1999)127<1693:OONLLM>2.0.CO;2.

_ J. Atmos. Oceanic Technol., 17, 105-120, https://doi.org/ 10.1175/1520-0426(2000)017<0105:RDOA > 2.0.CO;2.

Tuttle, J. D., V. N. Bringi, H. D. Orville, and F. J. Kopp, 1989: Multiparameter radar study of a microburst: Comparison with model results. J. Atmos. Sci., 46, 601-620, https://doi.org/ 10.1175/1520-0469(1989)046<0601:MRSOAM > 2.0.CO;2.

Virtanen, P., and Coauthors, 2020: SciPy 1.0: Fundamental algorithms for scientific computing in Python. Nat. Methods, 17, 261-272, https://doi.org/10.1038/s41592-019-0686-2.

Vivekanandan, J., D. S. Zrnić, S. M. Ellis, R. Oye, A. V. Ryzhkov, and J. Straka, 1999: Cloud microphysics retrieval using S-band dual-polarization radar measurements. Bull. Amer. Meteor. Soc., 80, 381-388, https://doi.org/10.1175/1520-0477(1999) $080<0381$ :CMRUSB $>2.0$. CO 2 .

Wegener, A., 1911: Thermodynamik der atmosphäre. Nature, 90, 31, https://doi.org/10.1038/090031a0.

Weiss, S. A., W. D. Rust, D. R. MacGorman, E. C. Bruning, and P. R. Krehbiel, 2008: Evolving complex electrical structures of the STEPS 25 June 2000 multicell storm.
Mon. Wea. Rev., 136, 741-756, https://doi.org/10.1175/ 2007MWR2023.1.

Wiens, K. C., S. A. Rutledge, and S. A. Tessendorf, 2005: The 29 June 2000 supercell observed during STEPS. Part II: Lightning and charge structure. J. Atmos. Sci., 62, 4151-4177, https://doi.org/10.1175/JAS3615.1.

Williams, E., C. M. Cooke, and K. A. Wright, 1985: Electrical discharge propagation in and around space charge clouds. J. Geophys. Res., 90, 6059-6070, https://doi.org/10.1029/ JD090iD04p06059.

— in severe Florida thunderstorms. Atmos. Res., 51, 245-265, https://doi.org/10.1016/S0169-8095(99)00011-3.

—, V. Mushtak, D. Rosenfeld, S. Goodman, and D. Boccippio, 2005: Thermodynamic conditions favorable to superlative thunderstorm updraft, mixed phase microphysics and lightning flash rate. Atmos. Res., 76, 288-306, https://doi.org/ 10.1016/j.atmosres.2004.11.009.

Zhu, Y., V. A. Rakov, M. D. Tran, and A. Nag, 2016: A study of National Lightning Detection Network responses to natural lightning based on ground truth data acquired at LOG with emphasis on cloud discharge activity. J. Geophys. Res. Atmos., 121, 14 651-14 660, https://doi.org/10.1002/ 2016JD025574. 